\title{
Upconversion nanoparticle as a theranostic agent for tumor imaging and therapy
}

\author{
Wenkai Fang* and Yanchun Wei ${ }^{\dagger}$ \\ Ministry of Education Key Laboratory of Laser \\ Life Science $\mathbb{E}$ Institute of Laser Life Science \\ College of Biophotonics South China Normal University \\ Guangzhou 510631, P. R. China \\ *fwkoneway@163.com \\ †weiyanchun@scnu.edu.cn
}

Received 14 November 2015

Accepted 2 March 2016

Published 16 May 2016

\begin{abstract}
Upconversion nanoparticles (UCNPs) as a promising material are widely studied due to their unique optical properties. The material can be excited by long wavelength light and emit visible wavelength light through multiphoton absorption. This property makes the particles highly attractive candidates for bioimaging and therapy application. This review aims at summarizing the synthesis and modification of UCNPs, especially the applications of UCNPs as a theranostic agent for tumor imaging and therapy. The biocompatibility and toxicity of UCNPs are also further discussed. Finally, we discuss the challenges and opportunities in the development of UCNP-based nanoplatforms for tumor imaging and therapy.
\end{abstract}

Keywords: Laser; upconversion material; bioimaging; toxicity.

\section{Introduction}

Optical imaging is an important technique used in the field of biomedical research because of its noninvasive, real-time and high magnification characteristics. Researchers have demonstrated various luminescence materials for optical bioimaging such as fluorescent proteins, ${ }^{1}$ organic dyes, ${ }^{2,3}$ metal complexes, ${ }^{4}$ gold nanorods ${ }^{5}$ and semiconductor quantum dots (QDs). ${ }^{6,7}$ Most of these fluorescence probes are based on single-photon excitation mechanism. In the bioimaging application of them, there are some limitations existing, including the low optical penetration depth in tissues, low signalto-noise ratio (SNR) caused by auto-fluorescence from the biological tissue, and the cell damage caused by the high-energy photons.

Comparing conventional fluorescence materials, an excellent imaging probe which is based on

$\dagger$ Corresponding author.

This is an Open Access article published by World Scientific Publishing Company. It is distributed under the terms of the Creative Commons Attribution 4.0 (CC-BY) License. Further distribution of this work is permitted, provided the original work is properly cited. 
upconversion luminescence (UCL) mechanism, is developed. UCL is an anti-Stokes' emission process by converting long wavelength irradiation into shorter wavelength light emission, such as near infrared light (NIR) to shorter NIR, visible (blue, green, red), or UV. Up to now, the efficient upconversion luminescence only occurred in the compounds doped with rare earth ions. In particular, under continuous wave $(\mathrm{CW})$ excitation at NIR, lanthanide(Ln)-doping upconversion nanoparticles (UCNPs) exhibit unique UCL properties, such as sharp emission line, long lifetime, a large anti-Stokes shift of several hundred nanometers, superior photostability and nonblinking. ${ }^{8}$ The UCL has several attractive pionts for bioimaging: one is that the NIR light excitation does less harm to the living cells; the second, high SNR due to the very low auto-fluorescence with the NIR excitation; third, the deep tissue penetration owing to the excitation and emission wavelengths both in the range of the biological optical window. Based on the advantages, UCNPs have been successfully studied applying in a wide biomedical fields, including cell tracking, lymphatic imaging, vascular imaging, tumor targeted imaging and therapy.

Theranostics is defined as the increasingly close link between diagnostics and therapy. The objective of theranostics is to enable the proper therapy via a right diagnostics to patients. ${ }^{9}$ Therefore, theranostics for tumor treatment is proposed to realize effective treatment. ${ }^{10,11}$ Owing to the unique optical character, UCNPs represent an excellent biological platform for diagnostics and tumor targeted therapy, and is a hopeful candidate for theronostic agent. In this review, we summarize the recent progress as regards the using of UCNPs for tumor imaging and therapy and give a prospect on bio-application of this promising material.

\section{UCL Mechanism of the Lanthanide- Doped Nanophosphors}

UCL has a very different luminescence mechanism comparing to conventional fluorophore. The excited state absorption (ESA) of UCNPs had already been demonstrated in papers. ${ }^{12}$ ESA takes the form of successive absorption of pump photons by a single ion and achieves high state due to the ladder-like structure of a simple multilevel system. Then, the ion releases its energy by emitting a photon and returns to the ground state (Fig. 1(a)). With a rapid development of spectroscopy, more upconversion mechanisms were discovered. Energy transfer upconversion (ETU) was first observed in $\mathrm{Yb}^{3+}-\mathrm{Tm}^{3+}$ co-doped glass. ${ }^{13}$ In ETU, a sensitized ion 1 sequentially provides energy for ion 2 as activator by the energy transfer process. ${ }^{14,15}$ The activator is excited to a higher state from which anti-Stokes emission originates (Fig. 1(b)). ${ }^{16}$ Around the same time, the cooperative sensitization $^{17}$ (CSU) and cooperative luminescence ${ }^{18}$ upconversion mechanisms were also discovered. In cooperative sensitization, two ions as sensitizers simultaneously transfer energy to an activator. The activated ion achieves a real excited state where upconverted luminescence occurs (Fig. 1(c)). Cooperative luminescence is the same as the cooperative sensitization except that the emitting state replaces the intermediate state. Besides the above, further possible upconversion mechanisms still is being proposed and studied. ${ }^{19}$

To implement the upconversion energy transfer as the above, the constructed UCNPs generally contain three parts: host, sensitizer and activator. The selection of host could influence the intensity of luminescence. An ideal host material should have low nonradiative losses and high radiative emission. Many compounds, such as oxides $\left(\mathrm{Y}_{2} \mathrm{O}_{3}\right.$, $\left.\mathrm{ZrO}_{2}, \mathrm{Gd}_{2} \mathrm{O}_{3}, \mathrm{La}_{2} \mathrm{O}_{3}, \mathrm{Lu}_{2} \mathrm{O}_{3}\right)$, fluorides $\left(\mathrm{NaYF}_{4}\right.$, $\mathrm{NaYbF}_{4}, \mathrm{NaLaF}_{4}, \mathrm{LaF}_{3}, \mathrm{GdF}_{3}$ ), phosphates, heavy halides $(\mathrm{GdOCl})$, oxysulfide $\left(\mathrm{Y}_{2} \mathrm{O}_{2} \mathrm{~S}\right)$, vanadates $\left(\mathrm{YVO}_{4}, \mathrm{GdVO}_{4}\right)$, have been studied as the host lattice for UCL. ${ }^{20-28}$ Following the researches, the fluorides have become the most famous host materials due to their low photon energies and high chemical stability. By selection of activators with different energy level distribution, various wavelength emission can be obtained. Hexagonal $\mathrm{NaYF}_{4}: \mathrm{Yb}^{3+} / \mathrm{Er}^{3+}$ usually exhibits green emission located at $510-570 \mathrm{~nm}\left({ }^{2} \mathrm{H}_{11 / 2}+{ }^{4} \mathrm{~S}_{3 / 2} \rightarrow{ }^{4} \mathrm{I}_{15 / 2}\right)$ and red emission located at 630 and $660 \mathrm{~nm}$ $\left({ }^{2} \mathrm{~F}_{9 / 2} \rightarrow{ }^{4} \mathrm{I}_{15 / 2}\right)$. For $\quad \mathrm{Yb}^{3+}, \quad \mathrm{Tm}^{3+}$ co-doped UCNPs, its emissions center at $451\left({ }^{1} \mathrm{D}_{2} \rightarrow{ }^{3} \mathrm{~F}_{4}\right)$, $481\left({ }^{1} \mathrm{G}_{4} \rightarrow{ }^{3} \mathrm{H}_{6}\right), 646\left({ }^{1} \mathrm{G}_{4} \rightarrow{ }^{3} \mathrm{~F}_{4}\right)$ and $800 \mathrm{~nm}$ $\left({ }^{3} \mathrm{H}_{4} \rightarrow{ }^{3} \mathrm{H}_{6}\right)$. NaYF $4: \mathrm{Yb}^{3+} / \mathrm{Er}^{3+}$ and $\mathrm{NaYF}_{4}$ : $\mathrm{Yb}^{3+} / \mathrm{Tm}^{3+}$ have been widely studied for tumor imaging and therapy in vivo. 


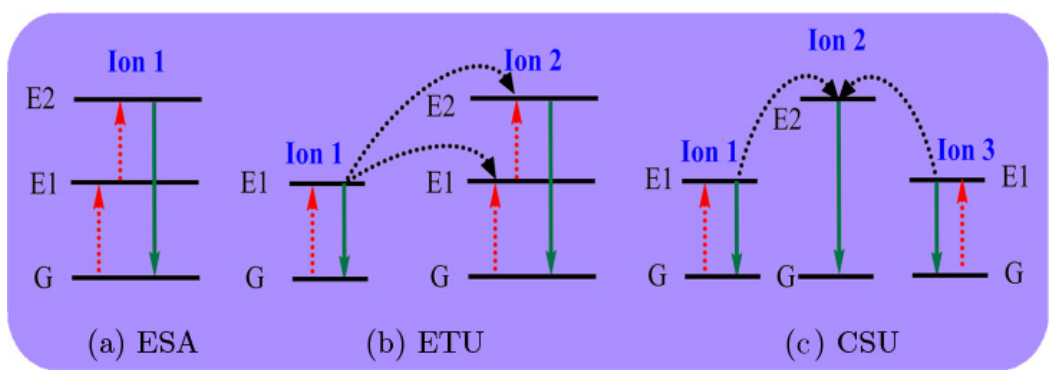

Fig. 1. Principles of UCL process for lanthanide-doped UCNPs. (a) ESA, (b) ETU and (c) CSU.

\section{Synthesis of UCNPs}

\subsection{Synthetic methods of UCNPs}

Development of facile synthesis methods for highquality UCNPs with suitable size, uniform shape, controlled composition and crystalline phase are important to tune their chemical and optical properties for imaging and therapy. To date, a range of synthetic approaches, such as hydro(solvo)thermal process, thermal decomposition, one-pot templatefree synthesis, sol-gel process, Ostwald-ripening method, and coprecipitation method, have been devoted to synthesize high-quality UCNPs.

\subsubsection{Hydro(solvo)thermal synthesis method}

In a typical hydrothermal method, reactions occur in a sealed environment under high pressure and temperature, usually above the critical point of the solvent to increase the reactivity and solubility of the inorganic elements. Compared with other types of synthetic methods, hydrothermal method has advantages to implement a set of reactions at the same time and create highly crystalline phase at much lower temperature. A basic hydrothermal method involves a few steps: first, mix rare-earth precursors with fluoride precursors in an aqueous solution, then place them in an autoclave (often Teflon-lined) and finally seal and heat them. The rare-earth precursors usually choose chlorides, nitrates or oxides of rare-earth ions. $\mathrm{HF}, \mathrm{NH}_{4} \mathrm{~F}$ or $\mathrm{NH}_{4} \mathrm{HF}_{2}$ are universally chosen as the fluoride precursor for synthesis of $\mathrm{LnF}_{3}$ nanocrystals, and $\mathrm{NaF}$ or $\mathrm{KF}$ commonly for $\mathrm{MLnF}_{4}$ nanocrystals. ${ }^{29,30}$

With the advantages of high purity and good homogeneity, the solvothermal synthesis method is another important technology for the preparation of UCNPs. Under the same conditions, the solvothermal process can achieve higher air pressure than the hydrothermal process due to its low boiling point, which not only shortens reactant times, but also benefits the crystallinity of products. Additionally, in a solvothermal system, the crystal growth can be controlled and products with different morphologies can be gained. ${ }^{31-35}$ Tian et al. reported a modified liquid-solid solution solvothermal strategy for synthesizing $\mathrm{Mn}^{2+}$-doped $\mathrm{NaYF}_{4}: \mathrm{Yb} /$ Er nanoparticles, which possess the rational manipulation of red and green upconversion luminescence, and the pure dark red emission $(650-670 \mathrm{~nm}) .{ }^{36}$

\subsubsection{Thermal decomposition method}

In a typical thermal decomposition procedure, organometallic compounds as precursors are decomposed in a high boiling point organic solvent with the assistance of surfactants at an elevated temperature. The common precursors are lanthanide metal ionic trifluoacetate salts; the solvent can be oleic acid (OA), oleylamine (OM), 1-octadecene (ODE) or trioctylphosphine oxide (TOPO), which can coordinate the metallic elements and the long hydrocarbon chain to prevent nanoparticle aggregation due to their typically functional capping group. Mai et al. ${ }^{37,38}$ have first developed a general synthetic strategy using the co-thermolysis of the trifluoroacetate precursors in $\mathrm{OA} / \mathrm{OM} / \mathrm{ODE}$ to synthesize fluoride-based nanocrystals. The composition of precursors, reaction time, temperature and coordination property of the solvent played critical roles in controlling the morphology, size, phase and UCL efficiency of the UCNP during the thermolysis process. Xie et al. ${ }^{39}$ and Wang et $a l .{ }^{40}$ reported the synthesis of monodispersed $\mathrm{Nd}^{3+}$-sensitized core-shell nanoparticles with narrow size distribution and regular morphology using thermal decomposition method. Vetrone et al. ${ }^{41}$ reported that the nanoparticles coated with a 
shell of $\mathrm{NaGdF}_{4}$ could minimize the luminescence quenching caused by the surface defects and surface-associated ligands. They also found that the UCL of the coated nanoparticles was more intense for the core/shell structure. In Cheng et al.'s work, the synthesized UCNPs were studied for biological application after modified with different hydrophilic molecules. ${ }^{42-44}$ A class of biocompatible UCNPs with largely amplified red-emissions were also developed by Han's group. ${ }^{45}$ The quantum yield of red emission reached 3.2, which is 15 -fold stronger than the known $\beta$-phase core/shell UCNPs. And the redemission of UCNPs could penetrate a deep-tissue $(>1.2 \mathrm{~cm})$ setting in vivo at a harmless laser power density. The deeper tumor treatment has been demonstrated by using a UCNP-PDT system. Shi's group successfully fabricated ultrasmall $\mathrm{NaGdF}_{4}$ nanodots $(2 \mathrm{~nm})$ with polyethylene glycol (PEG) modification. ${ }^{46}$ In their work, DTPA was chelated outside of the UCNPs to capture the potentially released $\mathrm{Gd}^{3+}$ ions. The synthesized nanodots were used for atherosclerotic plaque imaging and MR angiography.

\subsubsection{One-pot template-free synthesis}

Recently, hollow UCNPs have attracted crucial attention. Because they not only possess luminescence properties but also provide potential applications in the controlled storage or delivery of therapeutic drugs. Some groups used a templateassisted strategy to synthesize hollow nanoparticles for saving time and energy and allowing rapid production. However, the disadvantages of this strategy, such as low quantum yields and lengthy synthetic procedures and so on, still largely impeded the optimizing production and biomedical application. Alternatively, a template-free process to construct hollow upconversion structures has been developed for simplifying the preparation procedure. In Zhang et al.'s work, ${ }^{47}$ a facile solutionphase synthesis strategy was used for forming hollow cubic phase $\alpha-\mathrm{NaYF}_{4}$ nanoparticle. They demonstrated that the nanoscale growth of hollow particle with controlled size was induced by the Kirkendall effect. Yang and other researchers also employed the same strategy for synthesizing hollow $\mathrm{NaYF}_{4}: \mathrm{Yb} / \mathrm{Er}$ nanoparticles ${ }^{48}$ and coreshell-structured $\mathrm{Yb}(\mathrm{OH}) \mathrm{CO}_{3} @ \mathrm{YbPO}_{4}: \mathrm{Er}$ hollow microspheres. ${ }^{49}$ However, in these synthetic scheme, the corresponding oxides or carbonates precursors are still required. To further upgrade the templatefree strategy, the Ostwald ripening mechanism was studied and utilized in one-pot synthetic method of Ln-doped luminescent hollow structures. This method not only simplified the synthetic procedure, but also improved the nanoparticles yield. ${ }^{50} \mathrm{As}$ an example, Li reported an efficient, one-pot route for synthesizing sub-100 nm hydrophilic $\mathrm{NaYF}_{4}$-based upconversion hollow nanospheres in hydrothermal condition. ${ }^{51}$

\subsection{Optimization of UCNPs}

High luminescence efficiency is critical for UCNPs in theranostic application. Three general approaches have been implemented to improve the efficiency (Fig. 2), including (1) selection of efficient host materials; (2) plasmonic enhancement; (3) preparation of core/shell structures.

\subsubsection{Selection of host materials}

Selecting appropriate host materials is essential for high efficiency upconversion emission. Basically, a good host material should have high optical damage threshold, be transparent in the spectral range of interest, and be chemically stable. Up to now, $980 \mathrm{~nm}$ excited $\mathrm{NaYF}_{4}$ nanoparticles are the most efficient UCL host. Chen et al. reported that the intensity of $\mathrm{NaYF}_{4}: \mathrm{Yb}^{3+} / \mathrm{Tm}^{3+}$ nanocrystal NIR upconversion emission could be tuning, showing 43 times along with an increase in the relative content of $\mathrm{Yb}^{3+}$ ions from $20 \%$ to $100 \%$, with a corresponding decrease in the $\mathrm{Y}^{3+}$ content from $80 \%$ to $0 \%$. The synthetic ultrasmall $\mathrm{NaYbF}_{4}: 2 \%$ $\mathrm{Tm}^{3+}$ nanocrystals displayed $808 \mathrm{~nm}$ luminescence

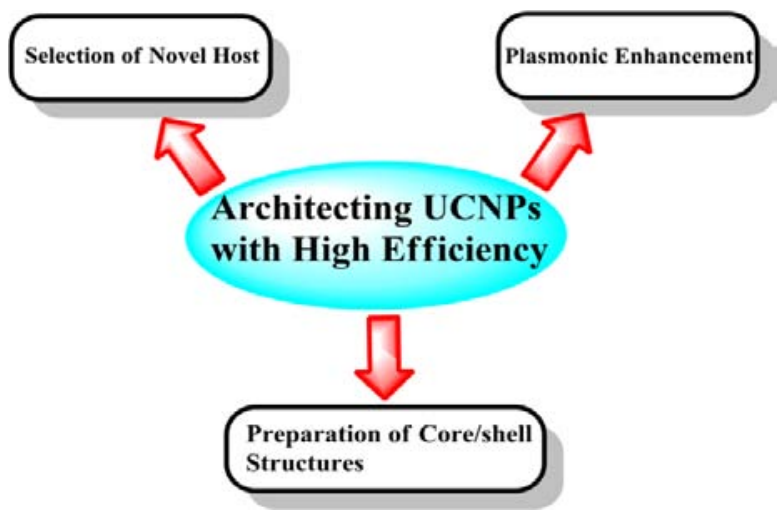

Fig. 2. General strategies to achieve the high efficiency of UCNPs. 
emission, which is 3.6 times more intense than $\mathrm{NaYF}_{4}: 20 \% \mathrm{Yb}^{3+} / 2 \% \mathrm{Tm}^{3+}$ nanocrystals. ${ }^{52}$

To obtain UCNPs with different emission and excitation wavelengths, the different doping ions $\mathrm{Er}^{3+}, \mathrm{Tm}^{3+}, \mathrm{Nd}^{3+}$ and $\mathrm{Ho}^{3+}$ are frequently used as activators. $\mathrm{Yb}^{3+}$ as a sensitizer to enhance the UCL efficiency is often co-doped with $\mathrm{Er}^{3+}, \mathrm{Tm}^{3+}$ and $\mathrm{Ho}^{3+}$, and it has a larger absorption cross section at around $980 \mathrm{~nm}$ than other lanthanide ions. The multicolor luminescent $\mathrm{NaYF}_{4}: \mathrm{Yb}^{3+}, \mathrm{Er}^{3+} \mathrm{UCNP}$ was studied by Liu et al. ${ }^{53}$ Similarly, the $\mathrm{Yb}^{3+} / \mathrm{Ho}^{3+}$ co-doped UCNP was chemically synthesized and investigated. ${ }^{54}$ Nyk et al. ${ }^{55}$ demonstrated a new approach for photoluminescence imaging in vitro and in vivo by synthesizing $\mathrm{Yb}^{3+}, \mathrm{Tm}^{3+}$ co-doped UCNPs. Wang et al. ${ }^{56}$ reported building a $\mathrm{Yb}^{3+}, \mathrm{Nd}^{3+}$ codoped core/shell structure to ensure successive $\mathrm{Nd}^{3+} \rightarrow \mathrm{Yb}^{3+} \rightarrow$ activator energy transfer. In order to decrease the cross-relaxation energy loss, they used a very low doping percentage of $\mathrm{Ln}^{3+}(<2 \mathrm{~mol} \%)$.

\subsubsection{Plasmonic enhancement}

The electromagnetic interaction of the metal with incident light of a specific wavelength can produce localized surface plasmon resonance (LSPR). LSPR can be used to enhance the efficiency of luminescence of UCNPs by setting an appropriate distance between the metallic structure and UCNPs. Through gold nanorod-based LSPR, Zhan et al. greatly enhanced UCL. They deposited unconversion materials on the corners of the gold nanorod, the significant overlap provided simultaneous enhancement of excitation and emission. ${ }^{57}$ Park et $a l .{ }^{58}$ presented a view of published works on plasmon enhanced upconversion, in regard to the effects of spacer layers and local heating, more detailed discussion on comparable classes of nanostructures, and the dynamics of the plasmon enhanced upconversion process.

\subsubsection{Preparation of core/shell structures}

The fabrication of core/shell architectures is another useful strategy to improve the luminescence of UCNPs. Because a shell with similar lattice constant grown around the UCNPs can reduce nonradiative decay losses of the surface luminescence. Chen et $a .^{24}$ reported a novel and biocompatible core/shell $\left(\alpha-\mathrm{NaYbF}_{4}: \mathrm{Tm}^{3+}\right) / \mathrm{CaF}_{2}$ nanoparticle, which exhibited highly efficient NIR-NIR upconversion. Through heteroepitaxial growth of a biocompatible $\mathrm{CaF}_{2}$ shell, the nanopaticle resulted in a 35-fold increase in the intensity of UCL from the core, surface quenching effect. Similarly, a core/shell $\mathrm{NaYbF}_{4}: \mathrm{Tm}^{3+} / \mathrm{NaGdF}_{4}$ nanoprobe was reported by another group for NIR-to-NIR UCL and magnetic resonance bimodal imaging (MRI). ${ }^{59}$ They demonstrated that the coated $\mathrm{NaGdF}_{4}$ shell increased the UCL efficiency of $\mathrm{Tm}^{3+}$ ions by about three times. Recently, Zhong group successfully designed a transition layer in the $\mathrm{NaYF}_{4}: \mathrm{Yb}, \mathrm{Er}, \mathrm{Nd} @ \mathrm{NaYF}_{4}$ core-shell structure to decrease the quenching interaction between $\mathrm{Er}^{3+}$ and $\mathrm{Nd}^{3+}$ and enhanced the luminescence of $800 \mathrm{~nm}$ excited UCNPs. ${ }^{60}$ Liu synthesized an core-shell UCNP excited with $795 \mathrm{~nm}$ by doping with the high-concentration $\mathrm{Nd}^{3+}(\sim 20 \mathrm{~mol}$ $\%),{ }^{39}$ markedly increased the UCL efficiency from that with the $\mathrm{Er}^{3+}$ or $\mathrm{Ho}^{3+}$.

\section{Biological Preparation of UCNPs}

\subsection{Surface functionalization of $\mathrm{UCNPs}$}

UCNPs produced by the methods in Sec. 3.1 are often hydrophobic due to the OA, OM, or TOPO molecules capping. To apply UCNPs in biological environment for imaging and therapy, suitable surface properties are required. Modification and functionalization are crucial steps to convert these hydrophobic UCNPs into water-soluble for enhancing the biocompatibility, and provide reactive groups for subsequent bio-conjugation, such as carboxyl $(-\mathrm{COOH})$, amino $\left(-\mathrm{NH}_{2}\right)$ or maleimide (MA) group. To date, common surface-functionalization process including hydrophobic/hydrophobic interaction, ligand exchange, layer-by-layer fabrication, silanization (coating with silica layer) and one-step synthesis of surface functionalized UCNPs have been developed (Fig. 3). ${ }^{61}$ Through these methods, $-\mathrm{COOH},-\mathrm{NH}_{2}$ or $\mathrm{MA}$ groups could be connected to UCNPs and further conjugated with biomolecules, such as folic acid (FA), peptide, protein, DNA and so on.

\subsubsection{Carboxylic acid (-COOH) group modification}

The $-\mathrm{COOH}$ group is particularly easy to react with the biological molecules with $-\mathrm{NH}_{2}$ groups. 


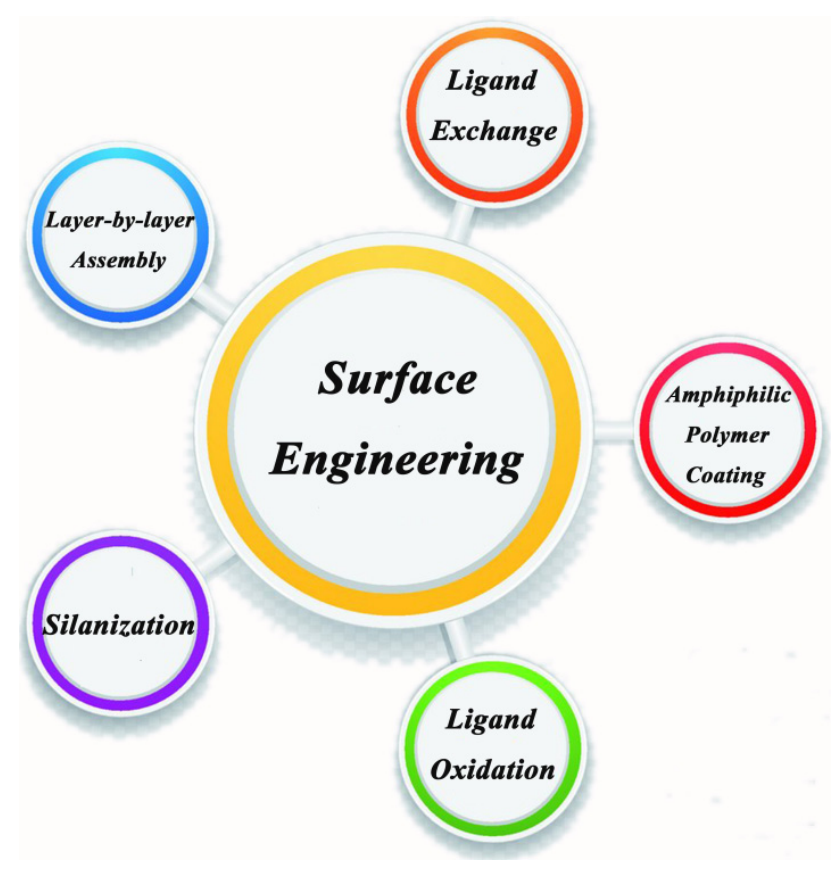

Fig. 3. Schematic illustration of general strategies for surface engineering of UCNPs.

Many ligands with carboxyl, such as 4,4-(hexafluoroisopropylidene) diphthalic anhydride (HDA) citrate, polyacrylic acid (PAA), thioglycolic acid (TGA), arachidonic acid (AA), MS methanesulfonic acid (MSA), dimercaptosuccinic acid (DMSA) and diacid PEG could be modified on the UCNPs surface through the surface-functionalization process. Prasad reported that they modified PAA on the surface of the OA-capped UCNPs through a general ligand exchange procedure. Chen et al. ${ }^{62}$ utilized the Lemieux-von Rudloff reagent to directly oxidize the OA-coated UCNPs for carboxylic acid group generation. Similarly, ozone was also used to directly oxidize the OA ligands on the surface of the UCNPs into $\left(\mathrm{HOOC}\left(\mathrm{CH}_{2}\right)_{7} \mathrm{COOH}\right)$ or azelaic aldehyde $\mathrm{HOOC}\left(\mathrm{CH}_{2}\right)_{7} \mathrm{CHO} .{ }^{63} \mathrm{In} \mathrm{Yi}$ and Chow's work, they employed a amphipathic reagent HOOC-PEG ${ }_{600}-\mathrm{COOH}$ to decorate the OM-coated $\mathrm{NaYF}_{4}: \mathrm{Yb}$,Er nanoparticles for carboxylic group functionalization. ${ }^{64}$

\subsubsection{Amine $\left(-\mathrm{NH}_{2}\right)$ group modification}

As carboxylic acid group, amine group can also be modified on UCNPs for conjugation of functional biomolecules with the carboxylic acid group. Hydrophilic ligands, such as poly(amidoamine) (PAMAM), azodicarbonamide (ADA), poly(ethylenimine) (PEI), diamino PEG, para-aminohippuric acid $(\mathrm{PAH})$, could provide $-\mathrm{NH}_{2}$ for the UCNPs surface. The amine densities conjugated on the surface of UCNP could be measured by the 9fluorenylmethyl chloroformate $(\mathrm{FmocCl})^{65}$ or the ninhydrin analysis method. ${ }^{66}$ The amine group modified UCNP not only displayed better stability in water solution than the hydrophobic group coated nanoparticles, but also provided the ability to conjugate with FA, biotin, antibody, and DNA that contain $-\mathrm{COOH}$ group. In studies, $\mathrm{PAH}$ functionalized upconversion hexagonal-phase nanoparticles were connected with biotin as fluorescent probes for bioimaging. ${ }^{67}$ PAMAM dendrimers modified $\mathrm{NaGdF}_{4}: \mathrm{Er}^{3+}, \mathrm{Yb}^{3+}$ upconverting nanoparticles (LnNPs) was used for the next molecular connection. ${ }^{68}$ In addition, Li reported a novel one-step synthetic strategy for AA-modified UCNPs using a hydrothermal reaction assisted by binary cooperative ligands (HR-BCL) ${ }^{65}$ This AAmodified UCNPs could further conjugate with FA for targeting overexpressed folate receptor on tumor cell surface. Another group synthesized PEI capped UCNPs and then used a reactive alkene to connect the PEI. ${ }^{69}$ The N-terminal cysteine of the cyclin D-targeting peptide $\left(\mathrm{P}_{1}\right)$ thus could react with the alkene to form UCNPs- $\mathrm{P}_{1}$.

\subsubsection{MA group modification}

MA moiety can react with many sulfydryl group modified biomolecules. MA-functionalized UCNPs generally can be composed of amine modified UCNPs and a functional linker for bio-conjugation. Xiong et al. reported the synthesis of MA-functionalized equivalents by using 6-maleimidohexanoic acid N-hydroxysuccinimide ester to modify amineterminated $\mathrm{NaYF}_{4}: \mathrm{Yb} / \mathrm{Er} / \mathrm{Tm}$ UCNPs. Then, the MA-UCNPs were linked with the thiolated cyclopeptide (Arg-Gly-Asp-Phe-Lys(mpa)) for targeted imaging. ${ }^{67,70}$ Maeda team ${ }^{71}$ structured a MAfunctionalized Er- $\mathrm{Y}_{2} \mathrm{O}_{3}$ by reacting MA-PEG-NHS with APTES-Er- $\mathrm{Y}_{2} \mathrm{O}_{3}$. So the MA-functionalized UCNPs could be linked with cyclic RGD peptide to specifically target to integrin $\alpha_{\mathrm{v}} \beta_{3}$ which is highly expressed in the tumor cell surface.

\subsection{UCNPs for tumor targeting in vivo}

Tumor specific targeting of UCNPs plays an key role in tumor diagnosis and treatment. Biological 
molecules, including antibodies, FA and peptides, have been used to coat on UCNPs to realize tumor targeting.

\subsubsection{FA-labeled UCNPs}

Many cancer cells can overexpress folate receptors (FR), which are only minimally distributed in normal tissues. Due to the high affinity of FA and FR, FA can be applied as a tumor targeting molecule. Because having nonimmunogenic character, high stability and ability to conjugate with a variety of molecules, FA already has attracted wide attention for tumor targeting of nanoparticles. ${ }^{72}$ Xiang and his co-workers first used FA to modify UCNPs for in vivo in 2009. ${ }^{73}$ Comparing the control group, obvious UCL signals were observed after injection of FA-modified UCNPs into HeLa tumor-bearing nude mouse over a day. Liu et al. also reported FAfunctionalized $\mathrm{NaYF}_{4}: \mathrm{Yb}^{3+}, \mathrm{Er}^{3+}-\mathrm{RB}$ nanoconjugates can improve the targeting efficacy in cancer cells for imaging. ${ }^{53}$

\subsubsection{Antibody-labeled UCNPs}

The high affinity interaction of antigen to antibody has become an important strategy of target recognition. Many researchers have reported antibodymodified UCNPs for target delivery and UCL imaging in vitro. For example, Jiang et al. constructed an anti-Her-2 antibody conjugated UCNP, to be used for interference RNA (siRNA) attaching and delivering to SK-BR-3 cells. ${ }^{74}$ However, less reports exhibit that antibody-functionalized UCNPs could successfully target to a specific tumor in animal model.

\subsubsection{Peptide-labeled UCNPs}

Small peptides are usually used to provide tissue penetration and better cellular uptake when introduced to animals. In the research, the arginineglycineasparatic acid (RGD) peptide plays a pivotal role in tumor targeting, because it has a high affinity to the $\alpha_{v} \beta_{3}$ integrin receptor which is highly expressed on tumor cell surface. For example, Zhou et al. has successfully constructed a photosensitizer pyropheophorbide a (Ppa) and RGD peptide comodified $\mathrm{NaYF}_{4}: \mathrm{Yb} /$ Er upconversion nanoparticle (UCNP-Ppa-RGD) for targeted integrin $\alpha_{\mathrm{v}} \beta_{3^{-}}$ positive U87-MG cells. ${ }^{75}$

\section{UCNPs Used as a Theranostic Agent for Tumor Imaging and Therapy}

\subsection{UCNPs for tumor optical imaging}

As an excellent optical materials, UCNPs were initially studied for imaging. Compared with the twophoton-absorbed QDs and organic dyes that require expensive pulse laser instrument, UCNPs can use the continuous NIR laser, emitted with an inexpensive diode, as the excitation light. The luminescence is relatively high and stable even at a high fluence rate of irradiation. The capability and feasibility of UCNPs for tumor imaging were demonstrated by many papers: $\mathrm{Wu}$ et al. ${ }^{76}$ reported that UCNPs have photostability, nonblinking and no autofluorescence for cell imaging. Hyeon's group ${ }^{77}$ studied the nonbleaching and nonblinking features of UCNPs when it served as an optical imaging nanoprobe. Xiong research team ${ }^{70}$ used RGD peptide to conjugate with MA-UCNPs. Their experiments showed that RGD peptide conjugated UCNPs could precisely target U87MG human glioblastoma tumors in mice and realized a vivid bioimaging (Fig. 4).

The great tissue penetration depth of light by use of UCNPs, has also been reported by Wei and others, comparing with the conventional fluoreophores. ${ }^{61,62,78,79}$ In Wei's work, the resluts showed that the UCNP had a very stable luminescence in various solution and high tissue penetration deepth with high SNR (Fig. 5). The UCNPs were loaded with the CA4P, an inhibitor of microtube, enhanced the permeability of blood vessel, and thus improved the nanoparticle targeting as well as the UCL imaging.

These studies indicate that UCNPs have many attractive features for imaging. Especially, the proposed imaging technique summarizes several individual properties, such as the deeper tissue penetration depth, the minimized autofluorescence of tissue and the high SNR in one integrated procedure, significantly improved the tumor-imaging capability.

\subsection{UCNPs for multifunctional biomedical imaging}

UCNPs can be used not only for UCL single imaging but also for the multifunctional imaging through combining with some other imaging techniques. The multifunctional lanthanide UCNPs used for UCL/ 


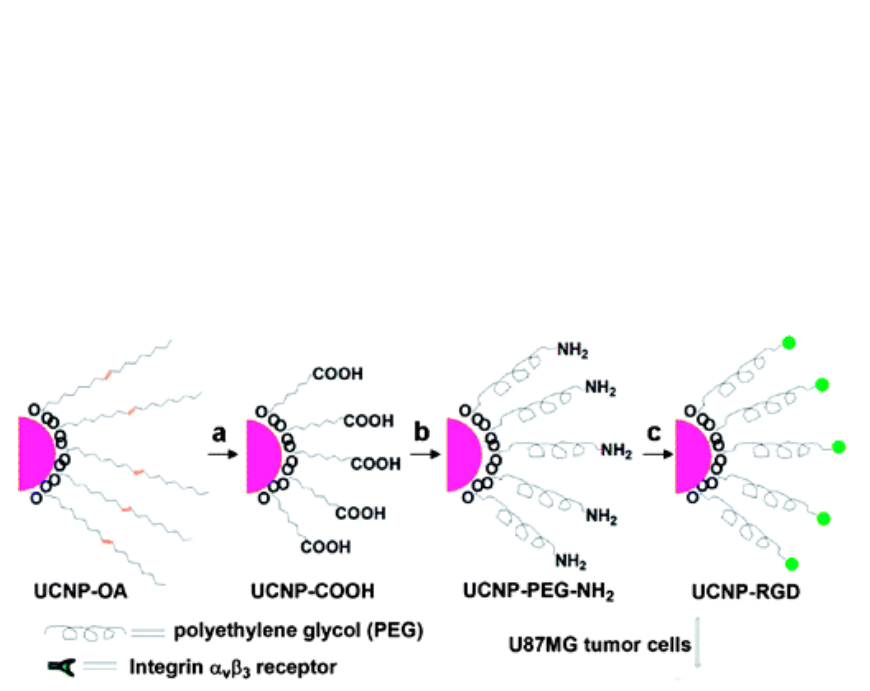

(a)

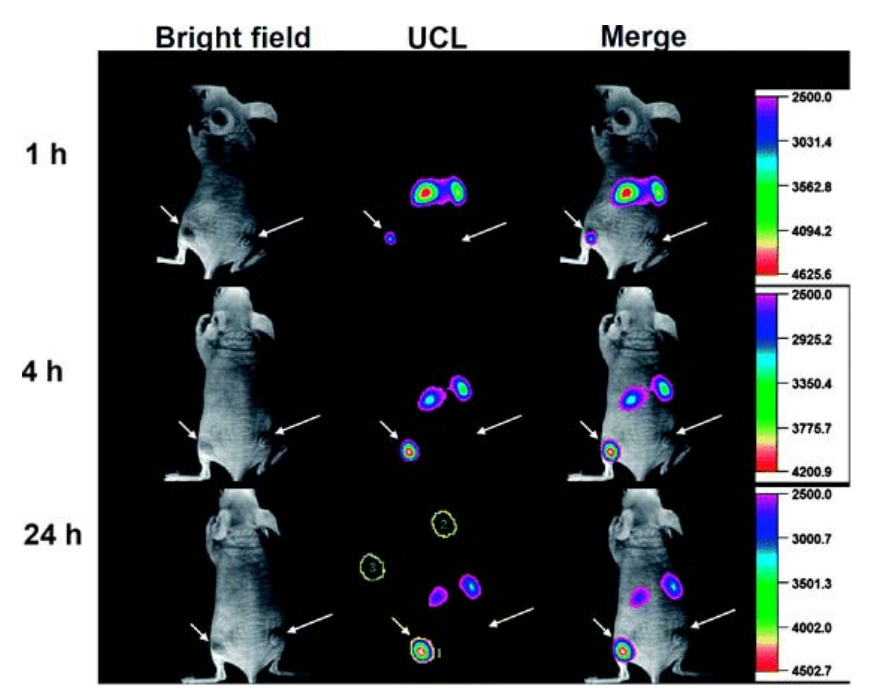

(b)

Fig. 4. In vivo tumor-targeted UCL imaging. (a) A scheme showing synthesis of UCNP-RGD. (b) Time-dependent in vivo UCL images of a mouse bearing a U87MG tumor (left hind leg, indicated by short arrows) and a MCF-7 tumor (right hind leg, indicated by long arrows) after intravenous injection of UCNP-RGD. (Reprinted with permission from "High contrast UCL targeted imaging in vivo using peptide-labeled nanophosphors". Copyright (2009) American Chemical Society.)

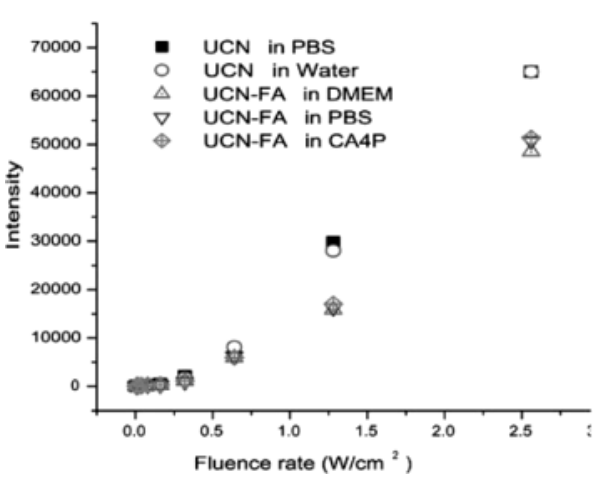

(a)

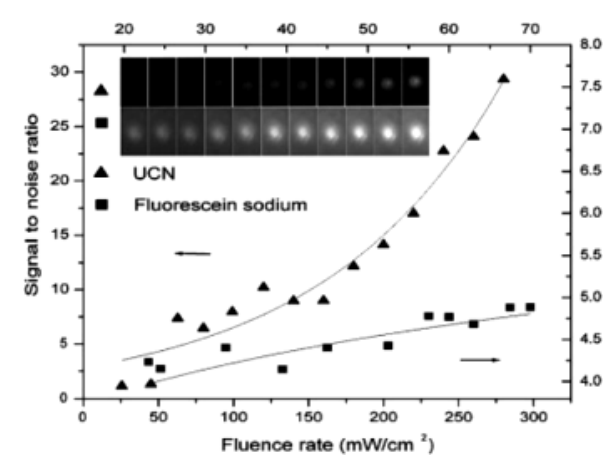

(c)

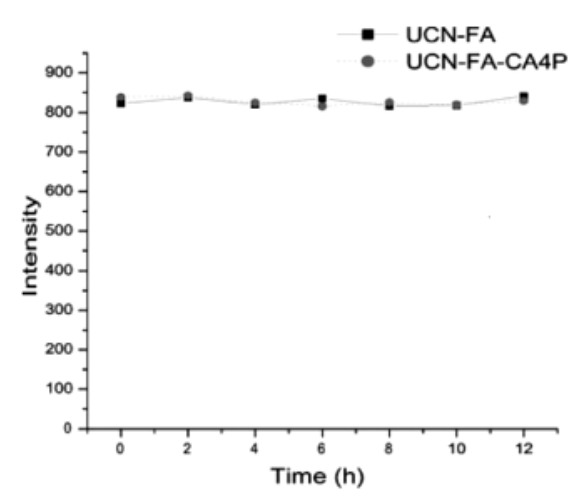

(b)

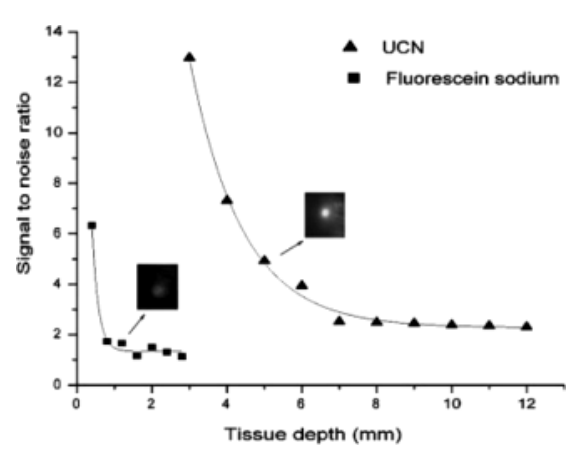

(d)

Fig. 5. (a) The intensity of UCNP-FA dissolved in different aqueous solutions. (b) The anti-photobleaching capability of UCNPFA. UCNP-FA was irradiated for $12 \mathrm{~h}$ continually with a laser $\left(980 \mathrm{~nm}, 800 \mathrm{~mW} \mathrm{~cm} \mathrm{~cm}^{-2}\right)$. (c) SNR of UCN and fluorescein sodium during laser excitation with different fluence rates. (d) SNR of the UCNPs and fluorescein sodium during laser excitation at different tissue depths. (Reproduced from "High-sensitivity in vivo imaging for tumors using a spectral up-conversion nanoparticle $\mathrm{NaYF}_{4}$ : $\mathrm{Yb}^{3+}, \mathrm{Er}^{3+}$ in cooperation with a microtubulin inhibitor" with permission from The Royal Society of Chemistry.) 
CT, UCL/MRI and UCL/PET multimodality bioimaging are discussed in this section.

\subsubsection{UCNPs for $T_{1}$-weighted and $T_{2}$-weighted $M R I$}

As a most commonly $\mathrm{T}_{1}$-weighted (Spin-lattice relaxation time) MRI agent, $\mathrm{Gd}^{3+}$ has a large paramagnetic moment due to its seven unpaired inner $4 \mathrm{f}$ electrons. Some groups used $\mathrm{NaGdF}_{4}$ as a host material to obtain magnetic UCNPs. ${ }^{59,80-84}$ For example, Johnson and his co-workers reported a 2.5-8.0 nm $\mathrm{NaGdF}_{4}: \mathrm{Yb}$,Er nanoparticle for the $\mathrm{T}_{1}$-weighted MRI. ${ }^{80}$ The $\mathrm{Gd}^{3+}$ relaxivity values increased from 3.0 to $7.2 \mathrm{mM}^{-1} \mathrm{~s}^{-1}$ with decreased particle size. The relaxivity of the $2.5 \mathrm{~nm}$ nanoparticles was almost twice than that of the clinical Gd-DTPA (Magnevist). Moreover, $\mathrm{KGdF}_{4},{ }^{85}$ $\mathrm{Gd}_{2} \mathrm{O}_{3},{ }^{86,87} \mathrm{GdVO}_{4},{ }^{22,88}$ and $\mathrm{GdPO}_{4}{ }^{89}$ codoped with $\mathrm{Yb}^{3+}$ and $\mathrm{Er}^{3+}\left(\right.$ or $\left.\mathrm{Tm}^{3+}\right)$, were also applied in $\mathrm{T}_{1}$-weighted MRI.

Another approach with $\mathrm{Gd}^{3+}$ for MRI was to dope the ions to the lanthanide UCNPs, such as the fabricated $\mathrm{NaLuF}_{4}: \mathrm{Gd}, \mathrm{Yb}, \mathrm{Tm}^{90}$ and $\mathrm{BaF}_{2}: \mathrm{Yb}$, $\mathrm{Tm} @ \mathrm{SrF}_{2}: \mathrm{Nd}, \mathrm{Gd}^{91}$ nanoparticles. Studies showed that $\mathrm{Gd}^{3+}$ co-doped nanoprobes could impart strong $\mathrm{T}_{1}$ and $\mathrm{T}_{2}$ (spin-spin relaxation time) for high contrast MRI. ${ }^{92-95}$

In addition, directly introducing $\mathrm{Gd}^{3+95}$ and modifying with gadopentetic acid (Gd-DTPA) ${ }^{96}$ onto the UCNP surface were also proposed for $\mathrm{T}_{1}$ weighted MRI.

$\mathrm{T}_{2}$-weighted MRI ability of nanostructures mainly rely on combination of UCNPs and superparamagnetic $\mathrm{Fe}_{3} \mathrm{O}_{4}$ nanoparticles. Shen et al. fabricated hetero-nanoparticles composed of $\mathrm{Fe}_{3} \mathrm{O}_{4}$ and $\mathrm{NaYF}_{4}: \mathrm{Yb}, \mathrm{Er}$ nanophosphors by a crosslinker anchoring process involving DDA or MUA. The magnetic saturation of the resultant hetero-nanoparticles was determined to be 9.25 and $7.05 \mathrm{emu} \mathrm{g}^{-1}$, respectively. ${ }^{97}$ Chen and co-workers developed a "neck-formation" method involving silica shielding to combine $\mathrm{Fe}_{3} \mathrm{O}_{4}$ and $\mathrm{NaYF}_{4}$ : $\mathrm{Yb}$,Er nanophosphor into hetero-nanoparticles. ${ }^{98}$ The saturation magnetization and $r_{2}$ values were measured as $89.8 \mathrm{emu}^{-1}$ and $211.76 \mathrm{~s}^{-1} \mathrm{mM}^{-1}(3.0 \mathrm{~T})$, respectively.

\subsubsection{UCNPs for positron emission tomography imaging}

By measuring the radioactivity, position emission tomography (PET) imaging has very deep tissue penetration for in vivo imaging. ${ }^{18} \mathrm{~F}$ is the most widespread radionuclide used in clinical PET imaging, due to its short half-life (110 min). Based on the affinity between $\mathrm{Ln}^{3+}$ and $\mathrm{F}^{-}$, Sun and coworkers had introduced radioactive ${ }^{18} \mathrm{~F}$ onto the surface of rare-earth nanoparticles, such as oxide, fluoride and hydroxide. ${ }^{99}$ The ${ }^{18} \mathrm{~F}$-labeling process only took $5 \mathrm{~min}$ in pure water and the yield of ${ }^{18} \mathrm{~F}$ labeling was more than $90 \%$. The bio-distribution of ${ }^{18}$ F-labeled rare-earth nanoparticles was further investigated by PET imaging.

\subsubsection{UCNPs for single-photon emission computed tomography imaging}

${ }^{153} \mathrm{Sm}$ as a $\gamma$-emitter has been incorporated into single photon emission computed tomography (SPECT) imaging probes used in preclinical and clinical diagnosis. Currently, two methods have been utilized to label lanthanide UCNPs with the radionuclide ${ }^{153} \mathrm{Sm}$ to exhibit the pharmacokinetics of them in vivo. One method is to dope ${ }^{153} \mathrm{Sm}$ into $\mathrm{Ln}^{3+}$-UCNPs. Li used a thermal decomposition method. ${ }^{100,101}$ and a one-step hydrothermal method ${ }^{102}$ to prepare $\mathrm{Tm}^{3+}, \mathrm{Yb}^{3+}$, and ${ }^{153} \mathrm{Sm}^{3+}$ co-doped $\mathrm{NaLuF}_{4}$ nanoparticles. The obtained radioactive ${ }^{153} \mathrm{Sm}$-doped $\mathrm{NaLuF}_{4}: \mathrm{Yb}, \mathrm{Tm}$ nanoparticles were accurately tracked by using SPECT imaging. What is more, they have also synthesized radioactive/upconverting $\quad \mathrm{NaLuF}_{4}:{ }^{153} \mathrm{Sm}, \mathrm{Yb}, \mathrm{Tm}$ nanoprobes and used them as a blood pool imaging agent for SPECT imaging. ${ }^{103}$ The other method is a rare-earth cation-exchange-based postlabeling strategy. ${ }^{104}$ The synthesized UCNPs were mainly captured by the mononuclear phagocyte system (liver and spleen). The SPECT imaging was then successfully used for liver and spleen monitoring.

\subsubsection{UCNPs for X-ray computed tomography (CT) imaging}

As is well-known, the higher atomic number and electron density of the computed tomography (CT) agent can have the higher attenuation coefficient. Lanthanide UCNPs have been reported to have higher atomic numbers than iodine, what made them useful as CT contrast agents. He et al. ${ }^{105}$ reported a novel $\mathrm{OA} /$ ionic liquid two-phase system combining the merits of thermal decomposition method and the IL-based strategy to synthesize 
high-quality lanthanide-doped $\mathrm{NaGdF}_{4}$ upconversion nanocrystals. The synthesized ultra-small size $(\sim 5 \mathrm{~nm}) \mathrm{NaGdF}_{4}: \mathrm{Yb}, \mathrm{Er}$ (Ho, Tm) upconversion nanocrystals are effective for dual-mode UCL imaging and CT imaging in vivo. Liu and co-workers reported a high contrast Yb-based nanoparticle modified with the biocompatible polymer DSPEPEG 2000 for X-ray CT imaging. ${ }^{106}$ Xing et al. used a PEGylated $\mathrm{NaYbF}_{4}: \mathrm{Tm}^{3+}$ nanopaticles with high $\mathrm{X}$-ray absorption coefficiency for both NIR-fluorescence bioimaging and CT. ${ }^{107}$

Grafting a CT contrast agent onto the UCNPs is another strategy for X-ray CT imaging of lanthanide UCNPs. Suitable small molecules, like Au, or $\mathrm{TaO}_{x}$ nanoparticles, are very popular as the X-ray CT contrast. ${ }^{108-110}$ By using $\beta-\mathrm{NaYF}_{4}: 18 \% \mathrm{Yb}^{3+}$, $2 \% \mathrm{Er}^{3+}$ nanoprobes modified with the contrast, Zhang et al. obtained an imaging platform with high visual sensitivity and tissue penetration. ${ }^{111}$ The nanoprobes possessed excellent UCL and remarkable CT contrast when the iodine concentration was increased from 0.018 to $0.969 \mathrm{mM}$.

Besides the above-mentioned imaging technique, multimodality imaging was also recommended for bioimaging to provide a more extensive information and accurate results. For example, Shen et al. fabricated a multishell $\mathrm{NaYF}_{4}: \mathrm{Yb} / \mathrm{Tm} @ \mathrm{Na}-$ $\mathrm{LuF}_{4} @ \mathrm{NaYF}_{4} @ \mathrm{NaGdF}_{4}$ nanoprobe for UCL, MRI and $\mathrm{CT}$ trimodal imaging. In the study, the core $\mathrm{NaYF}_{4}: \mathrm{Yb} / \mathrm{Tm}$ provided UCL; the first shell $\mathrm{NaLuF}_{4}$ was used to enhance the UCL and to serve as $\mathrm{CT}$ contrast; the outermost thin $\mathrm{NaGdF}_{4}$ layer provided the high longitudinal relaxivity $\left(r_{1}\right)$ for MRI; the transition shell of $\mathrm{NaYF}_{4}$ facilitated the formation of $\mathrm{NaGdF}_{4}$ shell and inhibited the energy transfer from inner activator to surface $\mathrm{Gd}^{3+} \cdot 112$

\subsection{UCNPs for tumor therapy}

UCNPs are not only applied in the field of bioimaging, they are also studied for therapeutic application. For example, photodynamic therapy (PDT) and photothermal therapy (PTT) have studied to utilize UCNPs as the theranostic agents. ${ }^{75}$ Through integrating the optical imaging capability and the therapeutical functions, the mulfunctional UCNP has become a powerful weapon for tumor disease fighting. ${ }^{113,114}$

\subsubsection{UCNPs for PDT}

Unlike surgery, chemotherapy and radiotherapy, PDT combines photosensitizer and light source to destruct tumor tissue through photodynamic reaction. Basic elements of PDT include oxygen, photosensitizer and light. Under specific wavelength laser irradiation, the photosensitizer is excited and transfers its energy to the surrounding oxygen to generate reactive oxygen species (ROS). ROS can induce oxidizing reaction with the adjacent biological molecules, thus causing cell damage and death.

However, PDT application is restricted by the limited penetration depth of visible light. The NIR light has a deeper tissue transmission but the photon energy is too low to excite the photosensitizer. Fortunately, UCNPs can do as a medium to receive the NIR light energy and transfer it to photosensitizer molecules for excitation. Thus, the NIR to visible UCNPs possess deep tissue penetration capability and have great superiority to be used in PDT. This capability has been confirmed by Zhou et al. ${ }^{75,115} \mathrm{In}$ Zhou and his co-workers' sequence work, they demonstrated that the UCNP modified with photosensitizer pyropheophorbide-a and RGD peptide could act as a NIR-excited photosensitizer for efficient tumor cell killing and deeper tumor treatment.

To efficiently load photosensitizers and transfer energy, several methods are applied: one method is coating a silica shell on the surface of UCNPs to form a heterogeneous core-shell carrier nanostructures; another is to attaching photosensitizers directly onto the surface of UCNPs through covalent bonding; the third is modifying polymers on the surface of UCNPs for photosensitizer conjugating.

Qian's group ${ }^{116}$ utilized mesoporous-silica-coated UCNPs loading a photosensitizer zinc phthalocyanine. The mesoporous silica could protect the photosensitizers from reaction with biological molecules in vivo. When the photosensitizers consequently released from the mesoporous silica, singlet oxygen was produced by a NIR laser exciting.

Ungun et al. ${ }^{117}$ structured a three-layer up-converting nanoprobe which outer layer modified with photosensitizer porphyrin and biocompatible PEG for PDT. In another study, the photosensitizer merocyanine 540 was directly attached on UCNP to be excited by infrared irradiation. ${ }^{118}$ The in vitro results showed that the UCNPs presented an effective PDT effect on MCF-7/AZ bladder cancer cells. 
$\mathrm{NaYF}_{4}: \mathrm{Yb} /$ Er has also been wrapped with Ocarboxymethyl chitosan to connect with the pyropheophorbide-a photosensitizer and the targeting molecule RGD peptide. ${ }^{63,69,76,115}$ In this photosensitizer loading method, the constructed nanoparticles successfully presented a significantly deeper therapeutic depth compared with conventional visible light triggered photosensitizer.

With regard to the application of the photosensitizers in UCNP-PDT, besides the above mentioned, some other specific photosensitizers were also studied. Guo et al. ${ }^{119}$ reported that the photosensitizer of tris-(bipyridine)ruthenium(II) (Ru (bpy) ${ }_{3}^{2+}$ ), which has a maximum absorption at $450 \mathrm{~nm}$, was functionalized on silica coated $\mathrm{NaYF}_{4}$ : $\mathrm{Yb}^{3+} / \mathrm{Tm}^{3+}$ nanoparticles. By absorbing the blue emission of $\mathrm{Tm}^{3+}, \mathrm{Ru}(\mathrm{bpy}){ }_{3}^{2+}$ could produce ${ }^{1} \mathrm{O}_{2}$ efficiently; Shan et al. ${ }^{120}$ reported that the mesotetraphenylporphine photosensitizer excited by the green emission of $\beta-\mathrm{NaYF}_{4}: \mathrm{Yb}^{3+} / \mathrm{Er}^{3+} \mathrm{UCNPs}$ could be used to damage HeLa cells; in Tian et al.'s work, ${ }^{121}$ photosensitizer chlorine e6 (Ce6), zinc phthalocyanine $(\mathrm{ZnPc})$ and methylene blue $(\mathrm{MB})$ were selected to modify on a specific synthesized red-emitting UCNP for PDT; the photosensitizer ZnPc modified multifunctional UCNPs constructed by Cui et al. ${ }^{122}$ could inhibit the deep-seated tumor up to $50 \%$; by comparison, the tumor inhibition ratio of the conventional visible light-activated PDT only reached $18 \%$ (Fig. 6).

In the most of UCNP-PDT studies, the imaging was simultaneously used to identify the nanoparticles localization for more precise tumor treatment purpose. ${ }^{76,115,123-128}$ They used photosensitizer for PDT, and UCL or other imaging method for particle/tumor localization. The integration improves the treatment effects and gives a promising biomedicine application strategy.

\subsubsection{UCNPs for PTT}

PTT uses a NIR light to excite photoabsorbers and then generates heat to damage cancer cells. Many groups have paid close attention to study PTT as a cancer therapies. Since UCNPs have its advantages

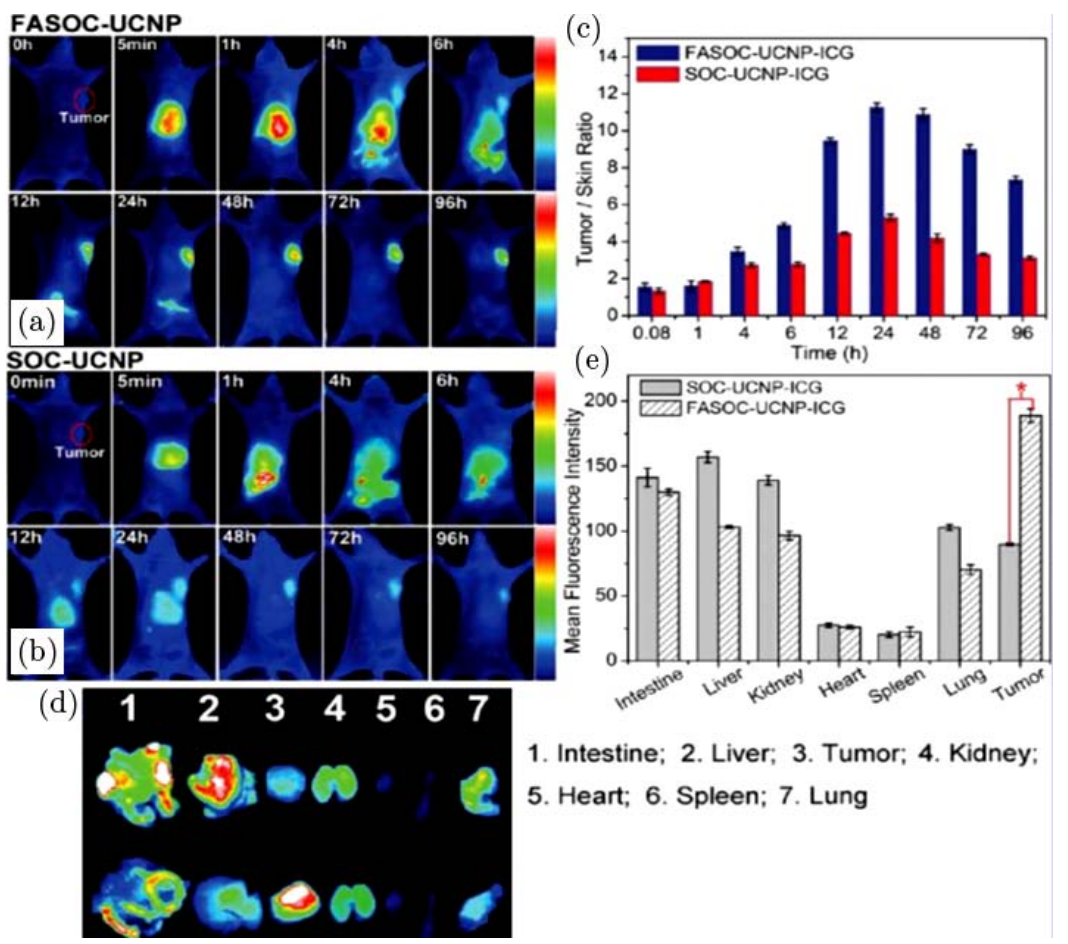

Fig. 6. In vivo tumor-targeting of the nanoconstructs. Fluorescence images of nude mice bearing Bel-7402 tumors with intravenously injection of (a) FASOC-UCNP-ICG and (b) SOC-UCNP-ICG; (c) tumor/skin ratio of tumor-bearing mice injected with different nanoconstructs; (d) fluorescence images of isolated organs separated from Bel-7402 tumor-bearing mice in different groups at $24 \mathrm{~h}$ postinjection; (e) semiquantification of FASOC-UCNP-ICG and SOC-UCNP-ICG in the isolated organs of mice with different injection. (Reprinted with permission from "in vivo targeted deep-tissue photodynamic therapy based near-infrared light triggered upconversion nanoconstruct". Copyright (2013) American Chemical Society.) 
on optical imaging and the optical absorbers loading, they have been studied for uses in PTT applications.

Dong et al. ${ }^{129}$ synthesized a core-shell $\mathrm{NaYF}_{4}$ : $\mathrm{Yb}^{3+}, \mathrm{Er}^{3+} @ \mathrm{Ag}$ nanoparticles with unique biofunctional specialty for imaging and tumor eradication. They observed the significantly photothermal induced death in both human hepatic cancer cells HepG2 and breast cancer cells BCap-37, which were incubated with the composite NPs in vitro and under $980 \mathrm{~nm}$ NIR excitation.

Additionally, by decorating ultra-small plasmonic $\mathrm{CuS}$ nanoparticles onto the surface of silicacoated UCNPs, another group ${ }^{130}$ constructed a novel multifunctional core/satellite nanotheranostic (CSNT) for integrated in vivo imaging and tumor treatment. These CSNTs could perform PTT thermal ablation and implement highly localized radiation dose to increase the radiation therapy efficiency both in vitro and in vivo (Fig. 7). The tumor could be entirely eliminated in 120 days under the associated interaction between photothermal absorption and the enhanced radiotherapy. Notably, the CSNTs showed nontoxic for the mice within a month. Through layer-by-layer self-assembly method, Cheng et al. ${ }^{108}$ created $\mathrm{Fe}_{3} \mathrm{O}_{4}$ coated $\mathrm{NaYF}_{4}: \mathrm{Yb}^{3+} / \mathrm{Er}^{3+} \mathrm{UCNPs}$, on top of which a thin gold shell was formed by seed-induced reduction growth. The photothermal cancer treatment mainly owed to the gold shell, which possess the surface plasmon resonance absorption.

\subsubsection{UCNPs for chemotherapy}

Similar to the application in PTT, UCNPs were used for chemotherapy. In the reported protocols,

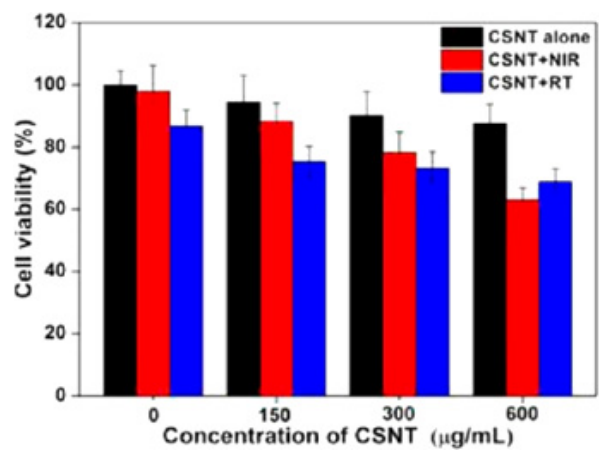

(a)

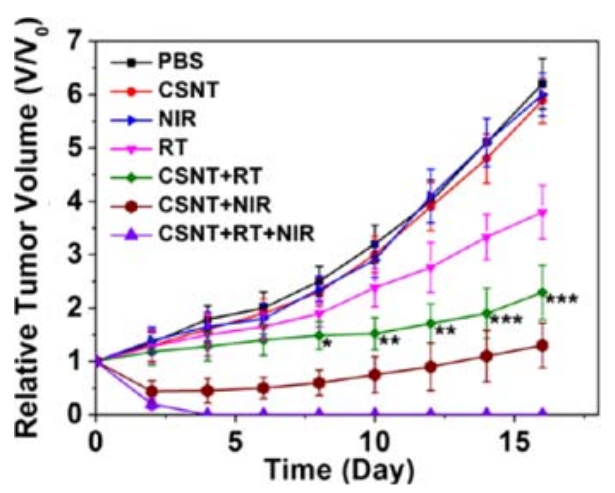

(c)

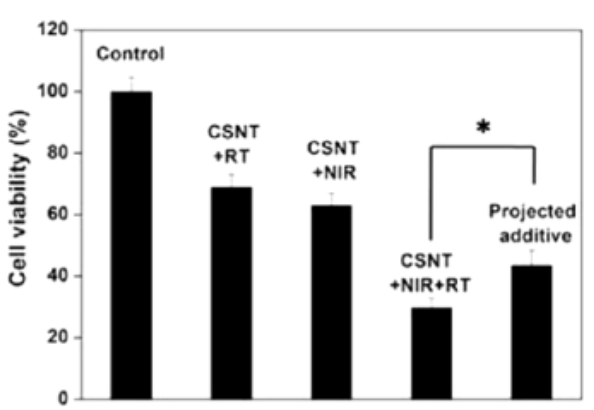

(b)

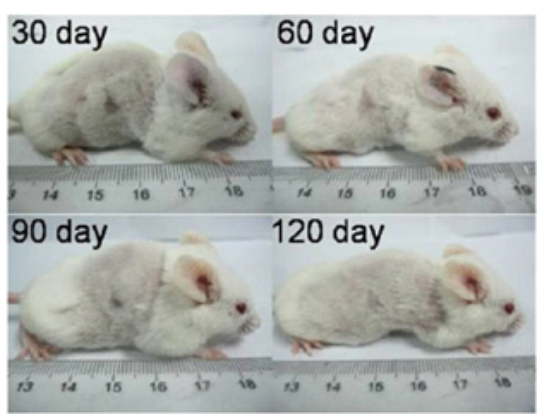

(d)

Fig. 7. (a) Quantitative analysis of the cell viability with CSNTs at varied concentrations with or without NIR-laser irradiation and RT. (b) Synergistic therapeutic effect of Hela cells that have taken up CSNTs subjected to RT, PTA, and the combined RT/ PTA treatments. (c) Time-dependent tumor growth curves of different groups of mice with various treatments. In all experiments, the power density of $980 \mathrm{~nm}$ NIR-laser and the radiation dose used for RT were kept constant at $1.5 \mathrm{~W} / \mathrm{cm}^{2}$ and $6 \mathrm{~Gy}$, respectively. (d) The photographs of mice in 30,60,90, and 120 days of treatment (group 7) showing the complete eradication of the tumor and no visible recurrences of the tumors in at least 120 days. (Reprinted with permission from "A core/satellite multifunctional nanotheranostic for in vivo imaging and tumor eradication by radiation/photothermal synergistic therapy". Copyright (2013) American Chemical Society.) 
UCL was utilized for chemo drug monitoring, including the distribution, localization, aggregation, and so on. To build up UCNP-based systems for drug delivery, mesoporous silica shells, hydrophobic pockets, and hollow spheres with mesoporous surface were studied. $\mathrm{Xu}$ et $a{ }^{131}$ projected an UCIO@Polymer multi-functional nanocomposite system by encapsulating hydrophobic UCNP together with iron oxide nanoparticles into the copolymer poly(styrene-block-allyl alcohol) $\left(\mathrm{PS}_{16}\right.$-b-PAA 10$)$. Doxorubicin was loaded into the UC-IO@Polymer to form UC-IO@Polymer-DOX complex for imaging-guided and magnetic-targeted drug delivery. Recently, Hou's group synthesized porous $\mathrm{NaYF}_{4}$ : Yb,Er@silica fiber, ${ }^{132} \quad \mathrm{Gd}_{2} \mathrm{O}_{3}: \mathrm{Er}_{\mathrm{n}} @ \mathrm{nSiO}_{2} @ \mathrm{mSiO}_{2}$ nanocomposite $^{133}$ and $\mathrm{Yb}(\mathrm{OH}) \mathrm{CO}_{3} @ \mathrm{YbPO}_{4}: \mathrm{Er}$ hollow spheres ${ }^{49}$ as the drug carriers. They demonstrated that the UCL could sensitively be used for monitoring and tracking the drug release.

Nitric oxide (NO) shows great potential for antirestenosis, anticancer and antibacterial. Therefore, successful NO-delivery is becoming one important issue in the biomedical application of NO. UCNPs have been successfully designed as a NIR sensitized system for NO carrying and therapy. ${ }^{134-136}$ In these studies, Roussin's black salt (RBS) was used as the NO yielding source. UCNPs coated with $\mathrm{SiO}_{2} /-$ $\mathrm{NH}^{3+}$, poly (dimethylsiloxane) composites, $\mathrm{mSiO}_{2}$ were used for RBS carrying and photo-triggered releasing for cancer therapy.

\subsubsection{UCNPs for gene therapy}

Gene therapy is the therapeutic delivery of nucleic acid polymers into a patient's cells to treat disease. RNA interference (RNAi) often is used in gene therapy, and represents a powerful, naturally occurring biological strategy for inhibition of gene expression. It is mediated through small interfering RNAs (siRNAs), which trigger specific mRNA degradation. The success of gene therapy is largely dependent on the development of the gene delivery vector. Utilizing UCNPs as gene carriers can simultaneously realize the gene delivery and its monitoring. Many studies have implemented this application of UCNPs. Jiang et al. ${ }^{74}$ reported that FA and anti-Her2 antibody were successfully conjugated with UCNPs for targeted delivery of siRNA and cell imaging. $\mathrm{NaYF}_{4}: \mathrm{Yb}$, Er was also employed as a carrier for BOBO-3-stained siRNAs delivery. ${ }^{137}$ The UCNPs transferred its energy to the BOBO-3 fluorescent acceptor through fluorescence resonance energy transfer (FRET) mechanism. Release of siRNA in cells gradually persisted for $24 \mathrm{~h}$ via intracellular FRET analysis. Recently, Jaya Kumar and co-workers developed a novel method to encapsulate photocaged DNA/siRNA molecules into the porous silica shell of the mesoporous silica-coated $\mathrm{NaYF}_{4}: \mathrm{Yb} / \mathrm{Tm}$ UCNPs for remotely controlling gene expression. ${ }^{138}$ The nanostructures not only increased the payload capacity, but also improved biocompatibility, offered a more efficient loading and delivery of the DNA/siRNA. Under NIR excitation, these photocaged plasmid DNA or siRNA could be activated by the UV light emitted from UCNPs and then induce expression or downregulation of the specific gene. The utilization of UCNPs co improved the depth of light penetration and the efficiency of the therapy.

\section{Toxicity of UCNPs}

The in vitro cytotoxicity and long-term living toxicity of UCNPs have been investigated by many researchers. In the process, MTS, MTT, CCK- 8 and mitochondrial metabolic activity assays ${ }^{139}$ were used. The results show that the fabricated UCNPs had a low cytotoxicity in the employed incubation time and drug concentration. The long-term living toxicity of UCNPs has also been evaluated by several proposed methods, such as the serum biochemistry assays, body weight measurement, histology and hematology analysis, behavior observation, and so on. Jalil and Zhang ${ }^{140}$ has controlled the dose of silica-coated $\mathrm{NaYF}_{4}: \mathrm{Yb}, \mathrm{Er}$ nanoparticles at $10 \mathrm{mg} \mathrm{kg}^{-1}$ in body of rats and no toxic effect was observed via body weight measurement. Through behavior observation, another group ${ }^{141}$ reported that mice, which were injected $\mathrm{NaGdF}_{4}$ : $\mathrm{Yb}$,Er,Tm nanoparticles, did not show abnormal behavior and could survive for more than one month.

Although all the experiments have shown a low toxicity in biomedical application, it is agreed by researches that further studies on toxicity of UCNPs are still necessary. More detailed investigation about the biomedical security should be conducted in the future work, especially on the longterm organ toxicity. 


\section{Challenges and Future Opportunities of UCNPs in Tumor Application}

In clinical procedure, theranostic agent is consumingly required. The unique character and advantages of UCNPs could not only greatly benefit the biomedical application but also showed encouraged results in PDT, PTT and chemotherapy application. As a promising theranositc agent, UCNP can work as efficient drug nanocarrier and sensitive optical indicator. In the future, UCNP would be well developed and their bio-application would be greatly improved. We believe that some important details in synthesis utility of the promising nanoparticles should be concerned in current. They can be concluded as below:

(1) To obtain the ultra-small, surface-hydrophilic and biocompatible high efficient UCNPs, exploring new synthetic method and surfacemodification process is still necessary. Uniforming growth rate of the crystal and reducing the crystal defects of UCNP are also important.

(2) The surface ligand of UCNPs is important for the biological stability and the UCL efficiency. The coordination ability, reaction activity, and stability of UCNPs all refer to the surface properties including zeta potential, functional groups and so on. Hence, further exploration of the surface chemistry of UCNPs is demanded.

(3) For high contrast imaging, a multifunctional nanoprobe should have the optimized radioactive, magnetic and optical properties. Although researchers have obtained some successful results, multimodal imaging based on multifunctional UCNPs, especially the targeting UCNPs, still need to be developed.

(4) Combining UCNP-based PDT or PTT with the guidance of UCL-based imaging has a great perspective to achieve more effective therapeutic effect in vitro and in vivo. But more efficient imaging-guided therapy which integrates drug delivery monitoring, tumor localization, optical therapy and treatment effect monitoring in a UCNP nanoplatform still need to be further investigated.

(5) Although a low cytotoxicity of the UCNPs has been demonstrated, further nanotoxicology and pharmacokinetics studies, including the dynamics of drug absorption, distribution, metabolism, elimation to the UCNPs with different shapes, sizes and surface coatings should be carefully confirmed.

\section{Conclusions}

In this review, we have described the recent developments of UCNPs in the design, synthesis and application in bioimaging and therapy. UCNPs have been recognized as a technological marvel with excellent optical properties including nonphotobleaching, nonblinking, low-toxicity, no autofluorescence interference and deep tissue penetration synthesis and application. As an effective tumor imaging and therapy nanoagent, it gives a promising future for biomedical application.

\section{Acknowledgments}

This research is supported by the National Natural Science Foundation of China (91539127; 61361160414), the Guangdong Natural Science Foundation (2015A030313394), and the Science and Technology Planning Project (2014A020212738) of Guangdong Province, China.

\section{References}

1. B. N. Giepmans, S. R. Adams, M. H. Ellisman, R. Y. Tsien, "The fluorescent toolbox for assessing protein location and function," Science 312, 217224 (2006).

2. T. Terai, T. Nagano, Fluorescent probes for bioimaging applications, Current Opin. Chem. Biol. 12, 515-521 (2008).

3. M. Beija, C. A. Afonso, J. M. Martinho, "Synthesis and applications of rhodamine derivatives as fluorescent probes," Chem. Soc. Rev. 38, 2410-2433 (2009).

4. S. V. Eliseeva, J.-C. G. Bünzli, "Lanthanide luminescence for functional materials and bio-sciences," Chem. Soc. Rev. 39, 189-227 (2010).

5. H. Liu, F. Zhan, F. Liu, M. Zhu, X. Zhou, D. Xing, "Visual and sensitive detection of viable pathogenic bacteria by sensing of RNA markers in gold nanoparticles based paper platform," Biosens. Bioelectron. 62, 38-46 (2014).

6. X. Michalet, F. F. Pinaud, L. A. Bentolila, J. M. Tsay, S. Doose, J. J. Li et al., "Quantum dots for live cells, in vivo imaging, and diagnostics," Science 307, 538-544 (2005). 
7. Y. Liao, X. Zhou, D. Xing, "Quantum dots and graphene oxide fluorescent switch based multivariate testing strategy for reliable detection of listeria monocytogenes," ACS Appl. Mater. Interfaces 6 , 9988-9996 (2014).

8. Y. Liu, D. Tu, H. Zhu, E. Ma, X. Chen, "Lanthanide-doped luminescent nano-bioprobes: From fundamentals to biodetection," Nanoscale 5, 1369-1384 (2013).

9. D. Peer, J. M. Karp, S. Hong, O. C. Farokhzad, R. Margalit, R. Langer, "Nanocarriers as an emerging platform for cancer therapy," Nat. Nanotechnol. 2, 751-760 (2007).

10. L. Wen, W. Ding, S. Yang, D. Xing, "Microwave pumped high-efficient thermoacoustic tumor therapy with single wall carbon nanotubes," Biomaterials 75, 163-173 (2016).

11. H. Qin, T. Zhou, S. Yang, D. Xing, "Fluorescence quenching nanoprobes dedicated to in vivo photoacoustic imaging and high-efficient tumor therapy in deep-seated tissue," Small 11, 2675-2686 (2015).

12. H. W. Leverenz, F. Urbach, "Introduction to the Luminescence of Solids," Phys. Today 3, 32-33 (2009).

13. F. Auzel, "Compteur quantique par transfert denergie entre deux ions de terres rares dans un tungstate mixte ET dans un verre," C. R. Hebd. Seances Acad. Sci. B 262, 1016 (1966).

14. T. Forster, Naturwiss 33, 166 (1946), Ann. Phys. 2, 55 (1948).

15. D. L. Dexter, "A theory of sensitized luminescence in solids," J. Chem. Phys. 21, 836-850 (1953).

16. F. E. Auzel, "Materials and devices using doublepumped-phosphors with energy transfer," Proc. IEEE 61, 758-786 (1973).

17. V. Ovsyankin, P. Feofilov, "Cooperative optical phenomena in condensed media," Phys.-Usp. 15, 354 (1972).

18. E. Nakazawa, S. Shionoya, "Cooperative luminescence in $\mathrm{YbPO}_{4}$," Phys. Rev. Lett. 25, 1710 (1970).

19. J. S. Chivian, W. Case, D. Eden, "The photon avalanche: A new phenomenon in $\mathrm{Pr}^{3+}$-based infrared quantum counters," Appl. Phys. Lett. 35, 124-125 (1979).

20. S. Sivakumar, P. R. Diamente, F. C. van Veggel, "Silica-coated $\mathrm{Ln}^{3+}$-doped $\mathrm{LaF}_{3}$ nanoparticles as robust down-and upconverting biolabels," Chemistr 12, 5878-5884 (2006).

21. H. Guo, N. Dong, M. Yin, W. Zhang, L. Lou, S. Xia, "Visible upconversion in rare earth iondoped $\mathrm{Gd}_{2} \mathrm{O}_{3}$ nanocrystals," J. Phys. Chem. B 108, 19205-19209 (2004).

22. W. Yin, L. Zhou, Z. Gu, G. Tian, S. Jin, L. Yan et al., "Lanthanide-doped $\mathrm{GdVO}_{4}$ upconversion nanophosphors with tunable emissions and their applications for biomedical imaging," J. Mater. Chem. 22, 6974-6981 (2012).

23. F. Evanics, P. Diamente, F. Van Veggel, G. Stanisz, R. Prosser, "Water-soluble $\mathrm{GdF}_{3}$ and $\mathrm{GdF}_{3} / \mathrm{LaF}_{3}$ nanoparticles physical characterization and NMR relaxation properties," Chem. Mater. 18, 24992505 (2006).

24. G. Chen, J. Shen, T. Y. Ohulchanskyy, N. J. Patel, A. Kutikov, Z. Li et al., " $\left(\alpha-\mathrm{NaYbF} 4: \mathrm{Tm}^{3+}\right) / \mathrm{CaF}_{2}$ core/shell nanoparticles with efficient near-infrared to near-infrared upconversion for high-contrast deep tissue bioimaging," ACS Nano 6, 8280-8287 (2012).

25. F. Vetrone, J.-C. Boyer, J. A. Capobianco, A. Speghini, M. Bettinelli, "Significance of $\mathrm{Yb}^{3+}$ concentration on the upconversion mechanisms in codoped $\mathrm{Y}_{2} \mathrm{O}_{3}: \mathrm{Er}^{3+}, \mathrm{Yb}^{3+}$ nanocrystals," J. Appl. Phys. 96, 661-667 (2004).

26. G. Chen, Y. Zhang, G. Somesfalean, Z. Zhang, Q. Sun, F. Wang, "Two-color upconversion in rareearth-ion-doped $\mathrm{ZrO}_{2}$ nanocrystals," Appl. Phys. Lett. 89, 3105 (2006).

27. X. Luo, W. Cao, "Blue, green, red upconversion luminescence and optical characteristics of rare earth doped rare earth oxide and oxysulfide," Sci. China Ser. B: Chem. 50, 505-513 (2007).

28. Y. Sun, H. Liu, X. Wang, X. Kong, H. Zhang, "Optical spectroscopy and visible upconversion studies of $\mathrm{YVO}_{4}$ : $\mathrm{Er}^{3+}$ nanocrystals synthesized by a hydrothermal process," Chem. Mater. 18, 27262732 (2006).

29. J. Liu, N. Li, R. Wu, Y. Zhao, Q. Zhan, S. He, "Sub-5-nm lanthanide-doped $\mathrm{ZrO}_{2} @ \mathrm{NaYF}_{4}$ nanodots as efficient upconverting probes for rapid scanning microscopy and aptamer-mediated bioimaging," Opt. Mater. Express 5, 1759-1771 (2015).

30. M. Wang, C.-C. Mi, W.-X. Wang, C.-H. Liu, Y.-F. $\mathrm{Wu}, \mathrm{Z} . \mathrm{-R}$. $\mathrm{Xu}$ et al., "Immunolabeling ans NIRexcited fluorescent imaging of HeLa cells by using $\mathrm{NaYF}_{4}$ : Yb, Er upconversion nanoparticles," Acs Nano 3, 1580-1586 (2009).

31. B. Tang, J. Ge, C. Wu, L. Zhuo, J. Niu, Z. Chen et al., "Sol-solvothermal synthesis and microwave evolution of $\mathrm{La}(\mathrm{OH})_{3}$ nanorods to $\mathrm{La}_{2} \mathrm{O}_{3}$ nanorods," Nanotechnology 15, 1273 (2004).

32. R. I. Walton, "Subcritical solvothermal synthesis of condensed inorganic materials," Chem. Soc. Rev. 31, 230-238 (2002).

33. Z. Chen, Q. Tian, Y. Song, J. Yang, J. Hu, "PEGmediated solvothermal synthesis of $\mathrm{NaYF}_{4}: \mathrm{Yb} / \mathrm{Er}$ superstructures with efficient upconversion luminescence," J. Alloys Comp. 506, L17-L21 (2010). 
34. T. He, W. Wei, L. Ma, R. Chen, S. Wu, H. Zhang et al., "Mechanism studies on the superior optical limiting observed in graphene oxide covalently functionalized with upconversion $\mathrm{NaYF}_{4}: \mathrm{Yb}^{3+} /$ Er $^{3+}$ nanoparticles," Small 8, 2163-2168 (2012).

35. Z. Li, Y. Zhang, "An efficient and user-friendly method for the synthesis of hexagonal-phase $\mathrm{NaYF}_{4}: \mathrm{Yb}, \mathrm{Er} / \mathrm{Tm}$ nanocrystals with controllable shape and upconversion fluorescence," Nanotechnology 19, 345606 (2008).

36. G. Tian, Z. Gu, L. Zhou, W. Yin, X. Liu, L. Yan et al., " $\mathrm{Mn}^{2+}$ Dopant-controlled synthesis of $\mathrm{NaYF}_{4}: \mathrm{Yb} / \mathrm{Er}$ upconversion nanoparticles for in vivo imaging and drug delivery," Adv. Mater. 24, 1226-1231 (2012).

37. H.-X. Mai, Y.-W. Zhang, L.-D. Sun, C.-H. Yan, "Highly efficient multicolor up-conversion emissions and their mechanisms of monodisperse $\mathrm{NaYF}_{4}: \mathrm{Yb}$, Er core and core/shell-structured nanocrystals," J. Phys. Chem. C 111, 13721-13729 (2007).

38. H.-X. Mai, Y.-W. Zhang, R. Si, Z.-G. Yan, L.-d. Sun, L.-P. You et al., "High-quality sodium rareearth fluoride nanocrystals: controlled synthesis and optical properties," J. Am. Chem. Soc. 128, 6426-6436 (2006).

39. X. Xie, N. Gao, R. Deng, Q. Sun, Q.-H. Xu, X. Liu, "Mechanistic investigation of photon upconversion in $\mathrm{Nd}^{3+}$-sensitized core-shell nanoparticles," $J$. Am. Chem. Soc. 135, 12608-12611 (2013).

40. F. Wang, R. Deng, X. Liu, "Preparation of coreshell $\mathrm{NaGdF}_{4}$ nanoparticles doped with luminescent lanthanide ions to be used as upconversionbased probes," Nat. Protoc. 9, 1634-1644 (2014).

41. F. Vetrone, R. Naccache, V. Mahalingam, C. G. Morgan, J. A. Capobianco, "The active-core/active-shell approach: A strategy to enhance the upconversion luminescence in lanthanide-doped nanoparticles," Adv. Funct. Mater. 19, 2924-2929 (2009).

42. L. Cheng, K. Yang, Y. Li, X. Zeng, M. Shao, S.-T. Lee et al., "Multifunctional nanoparticles for upconversion luminescence/MR multimodal imaging and magnetically targeted photothermal therapy," Biomaterials 33, 2215-2222 (2012).

43. L. Cheng, K. Yang, M. Shao, S.-T. Lee, Z. Liu, "Multicolor in vivo imaging of upconversion nanoparticles with emissions tuned by luminescence resonance energy transfer," J. Phys. Chem. C 115, 2686-2692 (2011).

44. L. Cheng, K. Yang, S. Zhang, M. Shao, S. Lee, Z. Liu, "Highly-sensitive multiplexed in vivo imaging using PEGylated upconversion nanoparticles," Nano Res. 3, 722-732 (2010).
45. A. Punjabi, X. Wu, A. Tokatli-Apollon, M. ElRifai, H. Lee, Y. Zhang et al., "Amplifying the red-emission of upconverting nanoparticles for biocompatible clinically used prodrug-induced photodynamic therapy," ACS Nano 8, 1062110630 (2014).

46. H. Xing, S. Zhang, W. Bu, X. Zheng, L. Wang, Q. Xiao et al., "Ultrasmall NaGdF4 nanodots for efficient MR angiography and atherosclerotic plaque imaging," Adv. Mater. 26, 3867-3872 (2014).

47. F. Zhang, Y. Shi, X. Sun, D. Zhao, G. D. Stucky, "Formation of hollow upconversion rare-earth fluoride nanospheres: Nanoscale kirkendall effect during ion exchange," Chem. Mater. 21, 5237$5243(2009)$.

48. D. Yang, X. Kang, Y. Dai, Z. Hou, Z. Cheng, C. Li et al., "Hollow structured upconversion luminescent $\mathrm{NaYF}_{4}: \mathrm{Yb}^{3+}, \mathrm{Er}^{3+}$ nanospheres for cell imaging and targeted anti-cancer drug delivery," Biomaterials 34, 1601-1612 (2013).

49. Z. Xu, Ma Pa, C. Li, Z. Hou, X. Zhai, S. Huang et al., "Monodisperse core-shell structured upconversion $\mathrm{Yb}(\mathrm{OH}) \mathrm{CO}_{3} @ \mathrm{YbPO}_{4}: \mathrm{Er}^{3+}$ hollow spheres as drug carriers," Biomaterials 32, 41614173 (2011).

50. M. K. Devaraju, S. Yin, T. Sato, "A fast and template free synthesis of $\mathrm{Tb}: \mathrm{Y}_{2} \mathrm{O}_{3}$ hollow microspheres via supercritical solvothermal method," Cryst. Growth Des. 9, 2944-2949 (2009).

51. G. Tian, L. Duan, X. Zhang, W. Yin, L. Yan, L. Zhou et al., "One-pot template-free synthesis of $\mathrm{NaYF}_{4}$ upconversion hollow nanospheres for bioimaging and drug delivery," Chem. 9, 1655-1662 (2014).

52. G. Chen, T. Y. Ohulchanskyy, R. Kumar, H. Ågren, P. N. Prasad, "Ultrasmall monodisperse $\mathrm{NaYF}_{4}: \mathrm{Yb}^{3+} / \mathrm{Tm}^{3+}$ nanocrystals with enhanced near-infrared to near-infrared upconversion photoluminescence," ACS Nano 4, 3163-3168 (2010).

53. K. Liu, X. Liu, Q. Zeng, Y. Zhang, L. Tu, T. Liu et al., "Covalently assembled NIR nanoplatform for simultaneous fluorescence imaging and photodynamic therapy of cancer cells," ACS Nano 6 , 4054-4062 (2012).

54. G.-S. Yi, G.-M. Chow, "Colloidal LaF 3 :Yb, Er, $\mathrm{LaF}_{3}: \mathrm{Yb}, \mathrm{Ho}$ and $\mathrm{LaF}_{3}: \mathrm{Yb}, \mathrm{Tm}$ nanocrystals with multicolor upconversion fluorescence," J. Mater. Chem. 15, 4460-4464 (2005).

55. M. Nyk, R. Kumar, T. Y. Ohulchanskyy, E. J. Bergey, P. N. Prasad, "High contrast in vitro and in vivo photoluminescence bioimaging using near infrared to near infrared up-conversion in $\mathrm{Tm}^{3+}$ and $\mathrm{Yb}^{3+}$ doped fluoride nanophosphors," Nano Lett. 8, 3834-3838 (2008). 
56. Y.-F. Wang, G.-Y. Liu, L.-D. Sun, J.-W. Xiao, J.C. Zhou, C.-H. Yan, " $\mathrm{Nd}^{3+}$-sensitized upconversion nanophosphors: Efficient in vivo bioimaging probes with minimized heating effect," ACS Nano 7, 7200-7206 (2013).

57. Q. Zhan, X. Zhang, Y. Zhao, J. Liu, S. He, "Tens of thousands-fold upconversion luminescence enhancement induced by a single gold nanorod," Laser Photonics Rev. 9, 479-487 (2015).

58. W. Park, D. Lu, S. Ahn, "Plasmon enhancement of luminescence upconversion," Chem. Soc. Rev. 44, 2940-2962 (2015).

59. G. Chen, T. Y. Ohulchanskyy, W. C. Law, H. Ågren, P. N. Prasad, "Monodisperse $\mathrm{NaYbF}_{4}$ : $\mathrm{Tm}^{3+} / \mathrm{NaGdF}_{4}$ core/shell nanocrystals with nearinfrared to near-infrared upconversion photoluminescence and magnetic resonance properties," Nanoscale 3, 2003-2008 (2011).

60. Y. Zhong, G. Tian, Z. Gu, Y. Yang, L. Gu, Y. Zhao et al., "Elimination of photon quenching by a transition layer to fabricate a quenching-shield sandwich structure for $800 \mathrm{~nm}$ excited upconversion luminescence of $\mathrm{Nd}^{3+}$-sensitized nanoparticles," Adv. Mater. 26, 2831-2837 (2014).

61. G. Chen, H. Qiu, P. N. Prasad, X. Chen, "Upconversion nanoparticles: Design, nanochemistry, and applications in theranostics," Chem. Rev. 114, 5161-5214 (2014).

62. Z. Chen, H. Chen, H. Hu, M. Yu, F. Li, Q. Zhang et al., "Versatile synthesis strategy for carboxylic acid-functionalized upconverting nanophosphors as biological labels," J. Am. Chem. Soc. 130, 30233029 (2008).

63. H. P. Zhou, C. H. Xu, W. Sun, C. H. Yan, "Clean and flexible modification strategy for carboxyl/aldehyde-functionalized upconversion nanoparticles and their optical applications," Adv. Funct. Mater. 19, 3892-3900 (2009).

64. G. S. Yi, G. M. Chow, "Synthesis of hexagonalphase $\mathrm{NaYF}_{4}: \mathrm{Yb}$, Er and $\mathrm{NaYF}_{4}: \mathrm{Yb}$, Tm nanocrystals with efficient up-conversion fluorescence," Adv. Funct. Mater. 16, 2324-2329 (2006).

65. T. Cao, Y. Yang, Y. Gao, J. Zhou, Z. Li, F. Li, "High-quality water-soluble and surface-functionalized upconversion nanocrystals as luminescent probes for bioimaging," Biomaterials 32, 29592968 (2011).

66. J. Zhou, L. Yao, C. Li, F. Li, "A versatile fabrication of upconversion nanophosphors with functional-surface tunable ligands," J. Mater. Chem. 20, 8078-8085 (2010).

67. L. Wang, R. Yan, Z. Huo, L. Wang, J. Zeng, J. Bao et al., "Fluorescence resonant energy transfer biosensor based on upconversion-luminescent nanoparticles," Angew. Chem. Int. Ed. Engl. 44, 6054-6057 (2005).

68. N. Bogdan, F. Vetrone, R. Roy, J. A. Capobianco, "Carbohydrate-coated lanthanide-doped upconverting nanoparticles for lectin recognition," $J$. Mater. Chem. 20, 7543-7550 (2010).

69. C.-F. Chan, M.-K. Tsang, H. Li, R. Lan, F. L. Chadbourne, W.-L. Chan et al., "Bifunctional upconverting lanthanide nanoparticles for selective in vitro imaging and inhibition of cyclin $\mathrm{D}$ as anticancer agents," J. Mater. Chem. B 2, 84-91 (2014).

70. L. Xiong, Z. Chen, Q. Tian, T. Cao, C. Xu, F. Li, "High contrast upconversion luminescence targeted imaging in vivo using peptide-labeled nanophosphors," Anal. Chem. 81, 8687-8694 (2009).

71. T. Zako, H. Nagata, N. Terada, A. Utsumi, M. Sakono, M. Yohda et al., "Cyclic RGD peptidelabeled upconversion nanophosphors for tumor cell-targeted imaging," Biochem. Biophys. Res. Commun. 381, 545-548 (2009).

72. J. Zhong, L. Wen, S. Yang, L. Xiang, Q. Chen, D. Xing, "Imaging-guided high-efficient photoacoustic tumor therapy with targeting gold nanorods," Nanomedicine (2015).

73. L.-Q. Xiong, Z.-G. Chen, M.-X. Yu, F.-Y. Li, C. Liu, C.-H. Huang, "Synthesis, characterization, and in vivo targeted imaging of amine-functionalized rare-earth up-converting nanophosphors," Biomaterials 30, 5592-5600 (2009).

74. S. Jiang, Y. Zhang, K. M. Lim, E. K. Sim, L. Ye, "NIR-to-visible upconversion nanoparticles for fluorescent labeling and targeted delivery of siRNA," Nanomedicine 11, 1499-1509 (2015).

75. A. Zhou, Y. Wei, B. Wu, Q. Chen, D. Xing, "Pyropheophorbide A and c(RGDyK) comodified chitosan-wrapped upconversion nanoparticle for targeted near-infrared photodynamic therapy," Mol. Pharm. 9, 1580-1589 (2012).

76. S. Wu, G. Han, D. J. Milliron, S. Aloni, V. Altoe, D. V. Talapin et al., "Non-blinking and photostable upconverted luminescence from single lanthanide-doped nanocrystals," Proc. Nat. Acad. Sci. 106, 10917-10921 (2009).

77. Y. I. Park, J. H. Kim, K. T. Lee, K.-S. Jeon, H. B. $\mathrm{Na}, \mathrm{J} . \mathrm{H}$. Yu et al., "Nonblinking and nonbleaching upconverting nanoparticles as an optical imaging nanoprobe and $\mathrm{T}_{1}$ magnetic resonance imaging contrast agent," Adv. Mater. 21, 4467 (2009).

78. Y. Wei, Q. Chen, B. Wu, A. Zhou, D. Xing, "Highsensitivity in vivo imaging for tumors using a spectral up-conversion nanoparticle $\mathrm{NaYF}_{4}$ : $\mathrm{Yb}^{3+}$, $\mathrm{Er}^{3+}$ in cooperation with a microtubulin inhibitor," Nanoscale 4, 3901-3909 (2012). 
79. J. Liu, R. Wu, N. Li, X. Zhang, Q. Zhan, S. He, "Deep, high contrast microscopic cell imaging using three-photon luminescence of $\beta-\left(\mathrm{NaYF}_{4}\right.$ : $\left.\mathrm{Er}^{3+} / \mathrm{NaYF}_{4}\right)$ nanoprobe excited by $1480-\mathrm{nm} \mathrm{CW}$ laser of only 1.5-mW," Biomed. Opt. Express 6, 1857-1866 (2015).

80. N. J. Johnson, W. Oakden, G. J. Stanisz, R. Scott Prosser, F. C. van Veggel, "Size-tunable, ultrasmall $\mathrm{NaGdF}_{4}$ nanoparticles: Insights into their $\mathrm{T}_{1}$ MRI contrast enhancement," Chem. Mater. 23, 3714-3722 (2011).

81. Y. Hou, R. Qiao, F. Fang, X. Wang, C. Dong, K. Liu et al., " $\mathrm{NaGdF}_{4}$ nanoparticle-based molecular probes for magnetic resonance imaging of intraperitoneal tumor xenografts in vivo," ACS Nano 7, 330-338 (2012).

82. K. A. Abel, J.-C. Boyer, Veggel FCv, "Hard proof of the $\mathrm{NaYF}_{4} / \mathrm{NaGdF}_{4}$ nanocrystal core/shell structure," J. Am. Chem. Soc. 131, 14644-14645 (2009).

83. Y. Deng, H. Wang, W. Gu, S. Li, N. Xiao, C. Shao et al., "Ho" doped $\mathrm{NaGdF}_{4}$ nanoparticles as MRI/optical probes for brain glioma imaging," $J$. Mater. Chem. B 2, 1521-1529 (2014).

84. H. Guo, Z. Li, H. Qian, Y. Hu, I. N. Muhammad, "Seed-mediated synthesis of $\mathrm{NaYF}_{4}: \mathrm{Yb}, \mathrm{Er} /$ $\mathrm{NaGdF}_{4}$ nanocrystals with improved upconversion fluorescence and MR relaxivity," Nanotechnology 21, 125602 (2010).

85. H.-T. Wong, F. Vetrone, R. Naccache, H. L. W. Chan, J. Hao, J. A. Capobianco, "Water dispersible ultra-small multifunctional $\mathrm{KGdF}_{4}$ : $\mathrm{Tm}^{3+}$, $\mathrm{Yb}^{3+}$ nanoparticles with near-infrared to near-infrared upconversion," J. Mater. Chem. 21, 1658916596 (2011).

86. G. K. Das, B. C. Heng, S.-C. Ng, T. White, J. S. C. Loo, L. D'Silva et al., "Gadolinium oxide ultranarrow nanorods as multimodal contrast agents for optical and magnetic resonance imaging," Langmuir 26, 8959-8965 (2010).

87. L. Zhou, Z. Gu, X. Liu, W. Yin, G. Tian, L. Yan et al., "Size-tunable synthesis of lanthanide-doped $\mathrm{Gd}_{2} \mathrm{O}_{3}$ nanoparticles and their applications for optical and magnetic resonance imaging," $J$. Mater. Chem. 22, 966-974 (2012).

88. X. Kang, D. Yang, Y. Dai, M. Shang, Z. Cheng, X. Zhang et al., "Poly (acrylic acid) modified lanthanide-doped $\mathrm{GdVO}_{4}$ hollow spheres for up-conversion cell imaging, MRI and $\mathrm{pH}$-dependent drug release," Nanoscale 5, 253-261 (2013).

89. M. L. Debasu, D. Ananias, S. L. Pinho, C. F. Geraldes, L. D. Carlos, J. Rocha, "(Gd, Yb, Tb) $\mathrm{PO}_{4}$ up-conversion nanocrystals for bimodal luminescence-MR imaging," Nanoscale 4, 5154-5162 (2012).
90. S. Zeng, J. Xiao, Q. Yang, J. Hao, "Bi-functional $\mathrm{NaLuF}_{4}: \mathrm{Gd}^{3+} / \mathrm{Yb}^{3+} / \mathrm{Tm}^{3+}$ nanocrystals: Structure controlled synthesis, near-infrared upconversion emission and tunable magnetic properties," J. Mater. Chem. 22, 9870-9874 (2012).

91. D. Chen, Y. Yu, F. Huang, H. Lin, P. Huang, A. Yang et al., "Lanthanide dopant-induced formation of uniform sub-10 nm active-core/active-shell nanocrystals with near-infrared to near-infrared dual-modal luminescence," J. Mater. Chem. 22, 2632-2640 (2012).

92. R. Kumar, M. Nyk, T. Y. Ohulchanskyy, C. A. Flask, P. N. Prasad, "Combined optical and MR bioimaging using rare earth ion doped $\mathrm{NaYF}_{4}$ nanocrystals," Adv. Funct. Mater. 19, 853-859 (2009).

93. C.-C. Huang, W. Huang, C.-H. Su, C.-N. Feng, W.-S. Kuo, C.-S. Yeh, "A general approach to silicate nanoshells: Gadolinium silicate and gadolinium silicate: Europium nanoshells for dual-modality optical and MR imaging," Chem. Commun. 23, 3360-3362 (2009).

94. G. Ren, S. Zeng, J. Hao, "Tunable multicolor upconversion emissions and paramagnetic property of monodispersed bifunctional lanthanide-doped $\mathrm{NaGdF}_{4}$ nanorods," J. Phys. Chem. C 115, 2014120147 (2011).

95. Q. Liu, Y. Sun, C. Li, J. Zhou, C. Li, T. Yang et al., ${ }^{118}$ F-labeled magnetic-upconversion nanophosphors via rare-earth cation-assisted ligand assembly," Acs Nano 5, 3146-3157 (2011).

96. A. Xia, M. Chen, Y. Gao, D. Wu, W. Feng, F. Li, " $\mathrm{Gd}^{3+}$ complex-modified $\mathrm{NaLuF}_{4}$-based upconversion nanophosphors for trimodality imaging of NIR-to-NIR upconversion luminescence, X-Ray computed tomography and magnetic resonance," Biomaterials 33, 5394-5405 (2012).

97. J. Shen, L.-D. Sun, Y.-W. Zhang, C.-H. Yan, "Superparamagnetic and upconversion emitting $\mathrm{Fe}_{3} \mathrm{O}_{4} / \mathrm{NaYF}_{4}: \mathrm{Yb}$, Er hetero-nanoparticles via a crosslinker anchoring strategy," Chem. Commun. 46, 5731-5733 (2010).

98. F. Chen, S. Zhang, W. Bu, X. Liu, Y. Chen, Q. He et al., "A neckformation strategy for an antiquenching magnetic/upconversion fluorescent bimodal cancer probe," Chemistry 16, 11254-112560 (2010).

99. Y. Sun, M. Yu, S. Liang, Y. Zhang, C. Li, T. Mou et al., "Fluorine-18 labeled rare-earth nanoparticles for positron emission tomography (PET) imaging of sentinel lymph node," Biomaterials 32, 29993007 (2011).

100. Y. Sun, X. Zhu, J. Peng, F. Li, "Core-shell lanthanide upconversion nanophosphors as fourmodal probes for tumor angiogenesis imaging," ACS Nano 7, 11290-11300 (2013). 
101. J. Peng, Y. Sun, Q. Liu, Y. Yang, J. Zhou, W. Feng et al., "Upconversion nanoparticles dramatically promote plant growth without toxicity," Nano Res. 5, 770-782 (2012).

102. T. Cao, Y. Yang, Y. Sun, Y. Wu, Y. Gao, W. Feng et al., "Biodistribution of sub-10 nm PEG-modified radioactive/upconversion nanoparticles," Biomaterials 34, 7127-7134 (2013).

103. J. Peng, Y. Sun, L. Zhao, Y. Wu, W. Feng, Y. Gao et al., "Polyphosphoric acid capping radioactive/ upconverting $\mathrm{NaLuF}_{4}: \mathrm{Yb}, \mathrm{Tm},{ }^{153} \mathrm{Sm}$ nanoparticles for blood pool imaging in vivo," Biomaterials 34, 9535-9544 (2013).

104. Y. Sun, Q. Liu, J. Peng, W. Feng, Y. Zhang, P. Yang et al., "Radioisotope post-labeling upconversion nanophosphors for in vivo quantitative tracking," Biomaterials 34, 2289-2295 (2013).

105. M. He, P. Huang, C. Zhang, H. Hu, C. Bao, G. Gao et al., "Dual phase-controlled synthesis of uniform lanthanide-doped $\mathrm{NaGdF}_{4}$ upconversion nanocrystals via an $\mathrm{OA} /$ ionic liquid two-phase system for in vivo dual-modality imaging," Adv. Funct. Mater. 21, 4470-4477 (2011).

106. Y. Liu, K. Ai, J. Liu, Q. Yuan, Y. He, L. Lu, "A high-performance ytterbium-based nanoparticulate contrast agent for in vivo X-ray computed tomography imaging," Angew. Chem. Int. Ed. Engl. 51, 1437-1442 (2012).

107. H. Xing, W. Bu, Q. Ren, X. Zheng, M. Li, S. Zhang et al., "A $\mathrm{NaYbF}_{4}$ : $\mathrm{Tm}^{3+}$ nanoprobe for $\mathrm{CT}$ and NIR-to-NIR fluorescent bimodal imaging," Biomaterials 33, 5384-5393 (2012).

108. L. Cheng, K. Yang, Y. Li, J. Chen, C. Wang, M. Shao et al., "Facile preparation of multifunctional upconversion nanoprobes for multimodal imaging and dual-targeted photothermal therapy," Angew. Chem. Int. Ed. Engl. 123, 7523-7528 (2011).

109. H. Xing, W. Bu, S. Zhang, X. Zheng, M. Li, F. Chen et al., "Multifunctional nanoprobes for upconversion fluorescence, MR and CT trimodal imaging," Biomaterials 33, 1079-1089 (2012).

110. Q. Xiao, W. Bu, Q. Ren, S. Zhang, H. Xing, F. Chen et al., "Radiopaque fluorescence-transparent $\mathrm{TaO}_{x}$ decorated upconversion nanophosphors for in vivo $\mathrm{CT} / \mathrm{MR} / \mathrm{UCL}$ trimodal imaging," Biomaterials 33, 7530-7539 (2012).

111. G. Zhang, Y. Liu, Q. Yuan, C. Zong, J. Liu, L. Lu, "Dual modal in vivo imaging using upconversion luminescence and enhanced computed tomography properties," Nanoscale 3, 4365-4371 (2011).

112. J.-W. Shen, C.-X. Yang, L.-X. Dong, H.-R. Sun, K. Gao, X.-P. Yan, "Incorporation of computed tomography and magnetic resonance imaging function into $\mathrm{NaYF}_{4}: \mathrm{Yb} / \mathrm{Tm}$ upconversion nanoparticles for in vivo trimodal bioimaging," Analy. Chem. 85, 12166-12172 (2013).

113. Z. Gu, L. Yan, G. Tian, S. Li, Z. Chai, Y. Zhao, "Recent advances in design and fabrication of upconversion nanoparticles and their safe theranostic applications," Adv. Mater. 25, 3758-3779 (2013).

114. G. Tian, X. Zhang, Z. Gu, Y. Zhao, "Recent advances in upconversion nanoparticles-based multifunctional nanocomposites for combined cancer therapy," Adv. Mater. 27, 7692-7712 (2015).

115. A. Zhou, Y. Wei, Q. Chen, D. Xing, "In vivo nearinfrared photodynamic therapy based on targeted upconversion nanoparticles," J. Biomed. Nanotechnol. 11, 2003-2010 (2015).

116. H. S. Qian, H. C. Guo, P. C. L. Ho, R. Mahendran, Y. Zhang, "Mesoporous-Silica-coated up-conversion fluorescent nanoparticles for photodynamic therapy," Small 5, 2285-2290 (2009).

117. B. Ungun, R. K. Prud'Homme, S. J. Budijon, J. Shan, S. F. Lim, Y. Ju et al., "Nanofabricated upconversion nanoparticles for photodynamic therapy," Opt. Express 17, 80-86 (2009).

118. P. Zhang, W. Steelant, M. Kumar, M. Scholfield, "Versatile photosensitizers for photodynamic therapy at infrared excitation," J. Am. Chem. Soc. 129, 4526-4527 (2007).

119. Y. Guo, M. Kumar, P. Zhang, "Nanoparticle-based photosensitizers under CW infrared excitation," Chem. Mater. 19, 6071-6072 (2007).

120. J. Shan, S. J. Budijono, G. Hu, N. Yao, Y. Kang, Y. Ju et al., "Pegylated composite nanoparticles containing upconverting phosphors and meso-tetraphenyl porphine (TPP) for photodynamic therapy," Adv. Funct. Mater. 21, 2488-2495 (2011).

121. G. Tian, W. Ren, L. Yan, S. Jian, Z. Gu, L. Zhou et al., "Red-emitting upconverting nanoparticles for photodynamic therapy in cancer cells under nearinfrared excitation," Small 9, 1929-1938 (2013).

122. S. Cui, D. Yin, Y. Chen, Y. Di, H. Chen, Y. Ma et al., "In vivo targeted deep-tissue photodynamic therapy based on near-infrared light triggered upconversion nanoconstruct," ACS Nano 7, 676688 (2012).

123. F. Wang, D. Banerjee, Y. Liu, X. Chen, X. Liu, "Upconversion nanoparticles in biological labeling, imaging, and therapy," Analyst 135, 1839-1854 (2010).

124. M. E. Gindy, R. K. Prud'homme, "Multifunctional nanoparticles for imaging, delivery and targeting in cancer therapy," Expert Opin Drug 6, 865-878 (2009).

125. C. Wang, L. Cheng, Z. Liu, "Drug delivery with upconversion nanoparticles for multi-functional 
targeted cancer cell imaging and therapy," Biomaterials 32, 1110-1120 (2011).

126. N. M. Idris, M. K. Gnanasammandhan, J. Zhang, P. C. Ho, R. Mahendran, Y. Zhang, "In vivo photodynamic therapy using upconversion nanoparticles as remote-controlled nanotransducers," Nat. Med. 18, 1580-1585 (2012).

127. C. Wang, H. Tao, L. Cheng, Z. Liu, "Near-infrared light induced in vivo photodynamic therapy of cancer based on upconversion nanoparticles," Biomaterials 32, 6145-6154 (2011).

128. Z. Zhao, Y. Han, C. Lin, D. Hu, F. Wang, X. Chen et $a l .$, "Multifunctional core-shell upconverting nanoparticles for imaging and photodynamic therapy of liver cancer cells," Chemistry. 7, 830-837 (2012).

129. B. Dong, S. Xu, J. Sun, S. Bi, D. Li, X. Bai et al., "Multifunctional $\mathrm{NaYF}_{4}: \mathrm{Yb}^{3+}, \mathrm{Er}^{3+} @ \mathrm{Ag}$ core/ shell nanocomposites: Integration of upconversion imaging and photothermal therapy," J. Mater. Chem. 21, 6193-6200 (2011).

130. Q. Xiao, X. Zheng, W. Bu, W. Ge, S. Zhang, F. Chen et al., "A core/satellite multifunctional nanotheranostic for in vivo imaging and tumor eradication by radiation/photothermal synergistic therapy," $J$. Am. Chem. Soc. 135, 13041-13048 (2013).

131. H. Xu, L. Cheng, C. Wang, X. Ma, Y. Li, Z. Liu, "Polymer encapsulated upconversion nanoparticle/iron oxide nanocomposites for multimodal imaging and magnetic targeted drug delivery," Biomaterials 32, 9364-9373 (2011).

132. Z. Hou, C. Li, P. Ma, G. Li, Z. Cheng, C. Peng et al., "Electrospinning preparation and drug-delivery properties of an up-conversion luminescent porous $\mathrm{NaYF}_{4}: \mathrm{Yb}^{3+}, \mathrm{Er}^{3+} @$ Silica fiber nanocomposite," Adv. Funct. Mater. 21, 2356-2365 (2011).

133. Z. Xu, C. Li, Z. Hou, D. Yang, X. Kang, J. Lin, "Facile synthesis of an up-conversion luminescent and mesoporous $\mathrm{Gd}_{2} \mathrm{O}_{3}: \mathrm{Er}^{3+} @ \mathrm{nSiO}_{2} @ \mathrm{mSiO}_{2}$ nanocomposite as a drug carrier," Nanoscale $\mathbf{3}$, 661-667 (2011).

134. J. V. Garcia, J. Yang, D. Shen, C. Yao, X. Li, R. Wang et al., "NIR-triggered release of caged nitric oxide using upconverting nanostructured materials," Small 8, 3800-3805 (2012).

135. P. T. Burks, J. V. Garcia, R. GonzalezIrias, J. T. Tillman, M. Niu, A. A. Mikhailovsky et al., "Nitric oxide releasing materials triggered by near-infrared excitation through tissue filters," J. Am. Chem. Soc. 135, 18145-18152 (2013).

136. X. Zhang, G. Tian, W. Yin, L. Wang, X. Zheng, L. Yan et al., "Controllable generation of nitric oxide by near-infrared-sensitized upconversion nanoparticles for tumor therapy," Adv. Funct. Mater. 25, 3049-3056 (2015).

137. S. Jiang, Y. Zhang, "Upconversion nanoparticlebased FRET system for study of siRNA in live cells," Langmuir 26, 6689-6694 (2010).

138. M. K. G. Jayakumar, N. M. Idris, Y. Zhang, "Remote activation of biomolecules in deep tissues usingnearinfrared-to-UV upconversion nanotransducers," Proc. Nat. Acad. Sci. U.S.A. 109, 8483-8488 (2012).

139. T. Zhou, X. Zhou, D. Xing, "Controlled release of doxorubicin from graphene oxide based charge-reversal nanocarrier," Biomaterials 35, 4185-4194 (2014).

140. R. A. Jalil, Y. Zhang, "Biocompatibility of silica coated $\mathrm{NaYF}_{4}$ upconversion fluorescent nanocrystals," Biomaterials 29, 4122-4128 (2008).

141. J. Zhou, Y. Sun, X. Du, L. Xiong, H. Hu, F. Li, "Dual-modality in vivo imaging using rare-earth nanocrystals with near-infrared to near-infrared (NIR-to-NIR) upconversion luminescence and magnetic resonance properties," Biomaterials $\mathbf{3 1}$, 3287-3295 (2010). 